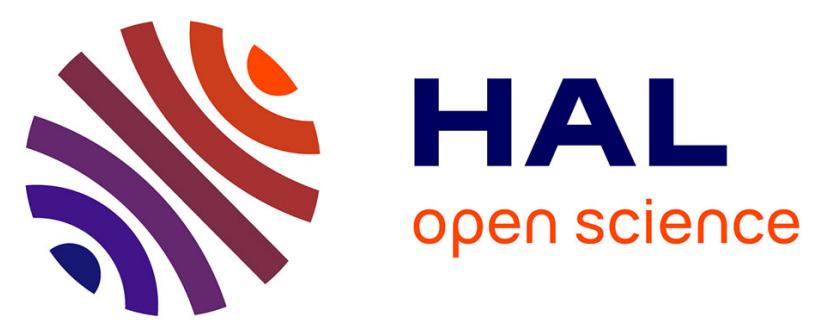

\title{
Controlling the Morphology of Film-Forming, Nanocomposite Latexes Containing Layered Double Hydroxide by RAFT-Mediated Emulsion Polymerization
}

Samuel Pearson, Marko Pavlovic, Thomas Augé, Valerian Torregrossa, Istvan Szilagyi, Franck D'agosto, Muriel Lansalot, Elodie Bourgeat-Lami, Vanessa Prevot

\section{To cite this version:}

Samuel Pearson, Marko Pavlovic, Thomas Augé, Valerian Torregrossa, Istvan Szilagyi, et al.. Controlling the Morphology of Film-Forming, Nanocomposite Latexes Containing Layered Double Hydroxide by RAFT-Mediated Emulsion Polymerization. Macromolecules, 2018, 51 (11), pp.3953 - 3966. 10.1021/acs.macromol.8b00541 . hal-01859493

\section{HAL Id: hal-01859493 https://hal.science/hal-01859493}

Submitted on 23 Dec 2021

HAL is a multi-disciplinary open access archive for the deposit and dissemination of scientific research documents, whether they are published or not. The documents may come from teaching and research institutions in France or abroad, or from public or private research centers.
L'archive ouverte pluridisciplinaire HAL, est destinée au dépôt et à la diffusion de documents scientifiques de niveau recherche, publiés ou non, émanant des établissements d'enseignement et de recherche français ou étrangers, des laboratoires publics ou privés. 


\section{Controlling the morphology of film-forming, nanocomposite latexes containing layered double hydroxide by RAFT-mediated emulsion polymerization}

Samuel Pearson, ${ }^{\mathrm{a}, \mathrm{b},{ }^{*}}$ Marko Pavlovic, ${ }^{\mathrm{c}}$ Thomas Augé, ${ }^{\mathrm{a}}$ Valerian Torregrossa, ${ }^{\mathrm{a}}$ Istvan Szilagyi, ${ }^{\mathrm{d}}$ Franck D’Agosto, ${ }^{a}$ Muriel Lansalot, ${ }^{a}$ Elodie Bourgeat-Lami, ${ }^{a},{ }^{*}$ Vanessa Prévot. ${ }^{\text {be, }}{ }^{*}$

${ }^{a}$ Univ Lyon, Université Claude Bernard Lyon 1, CPE Lyon, CNRS, UMR 5265, Chemistry, Catalysis, Polymers and Processes (C2P2), 43 Bvd. du 11 Novembre 1918, F-69616 Villeurbanne, France.

${ }^{\mathrm{b}}$ Université Clermont Auvergne, CNRS, UMR 6296, Institut de Chimie de Clermont-Ferrand, ICCF, F-63000 Clermont-Ferrand, France.

${ }^{\mathrm{c}}$ Department of Inorganic and Analytical Chemistry, University of Geneva, 30 Quai ErnestAnsermet, CH-1205 Geneva, Switzerland.

d MTA-SZTE Lendület Biocolloids Research Group, Department of Physical Chemistry and Materials Science, University of Szeged, 1 Rerrich Bela ter, 6720 Szeged, Hungary.

${ }^{\mathrm{e}}$ CNRS, UMR 6296, F-63178 Aubiè̀, France.

* Corresponding author. Email: samueljohnpearson@outlook.com, bourgeat@lcpp.cpe.fr, vanessa.prevot@uca.fr 


\title{
Keywords
}

Nanocomposites, layered double hydroxides, RAFT polymerization, emulsion polymerization, encapsulation

\begin{abstract}
Stable nanocomposite latexes with sandwich, encapsulated, or armored morphology were produced by starved-feed emulsion polymerization in the presence of layered double hydroxide (LDH) nanoparticles. Four statistical copolymers of acrylic acid (AA) and $n$-butyl acrylate (BA) were adsorbed on the LDH surface, and a film-forming methyl acrylate (MA)/BA (8:2 mass/mass) monomer feed was chosen to facilitate subsequent film formation under ambient conditions. $\mathrm{P}\left(\mathrm{AA}_{17.5}-c o-\mathrm{BA}_{17.5}\right)-\mathrm{R}(\mathrm{R}=\mathrm{RAFT}$ function) produced the sandwich morphology, while $\mathrm{P}\left(\mathrm{AA}_{7.5}-\mathrm{co}-\mathrm{BA}_{7.5}\right)-\mathrm{R}$ gave the encapsulated morphology, which is remarkable given that non-encapsulated morphologies are normally considered to be the preferred equilibrium structures for nancomposite particles. Adsorption behaviour and monomer conversion profiles were very similar for the two systems, and we tentatively ascribe the morphological difference to

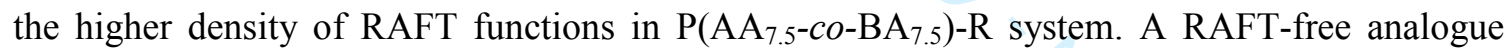
produced armored latexes, highlighting the importance of the RAFT function for promoting growth of the polymer shell from the nanoparticle surface.
\end{abstract}


For Table of Contents use only

Controlling the morphology of film-forming, nanocomposite latexes containing layered double hydroxide by RAFT-mediated emulsion polymerization

Samuel Pearson, Marko Pavlovic, Thomas Augé, Valerian Torregrossa, Istvan Szilagyi, Franck D’Agosto, Muriel Lansalot, Elodie Bourgeat-Lami, Vanessa Prévot

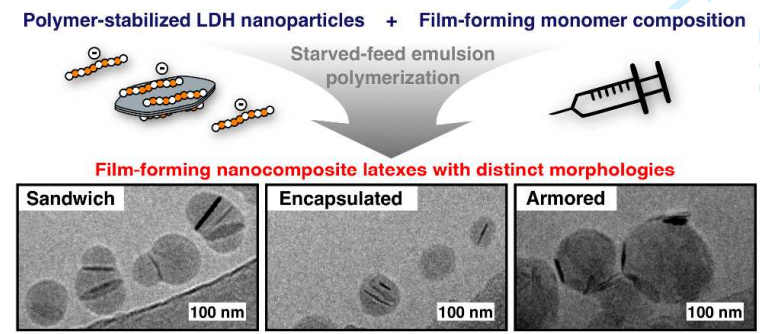




\section{Introduction}

Nanocomposites can offer dramatically improved properties compared to native polymer matrices. Incorporating a small amount of nanofiller into a polymer can for example impart large gains in hardness, toughness, impermeability, conductivity, and flame retardancy. ${ }^{1,2}$ The synthesis of nanocomposite materials is therefore of huge interest academically and industrially, particularly for the coating industry. Central to achieving such property enhancements is high dispersability of nanoparticles within the polymer matrix to ensure a high interfacial surface area, with the ultimate aim of controlling nanofiller orientation in resulting films.

The choice of nanofiller depends on the desired properties of the resulting films, with some inorganic particles simultaneously fulfilling more than one property enhancement. Layered double hydroxides (LDHs) are highly anisotropic, positively-charged inorganic clays which show great promise as nanofillers. ${ }^{3,4}$ Each layer in a LDH particle comprises of edge-shared octahedra containing a central di- or tri-valent metal $\left(\mathrm{M}^{2+}\right.$ or $\left.\mathrm{M}^{3+}\right)$ surrounded by hydroxide ions at the vertices. The presence of $\mathrm{M}^{3+}$ imparts a net positive charge to each layer, which is compensated by anions occupying the interlamellar spaces (conjointly with water molecules). Particle diameters typically range from tens of nanometers to several microns. A great diversity of LDH compositions with tunable dimensions can be attained by simply varying the nature and the proportions of the metal ions, anions, and synthesis conditions. LDHs have therefore been used for pollutant adsorption, carbon dioxide capture, catalysis, drug and gene delivery, biosensing, and in nanocomposites. ${ }^{5}$ As nanofillers, interest in LDHs stems from their significant enhancement of mechanical and thermal properties, flame retardancy, ${ }^{6,7}$ gas impermeability, ${ }^{8}$ and corrosion resistance. ${ }^{9,}{ }^{10}$ When employed in nanocomposites, the LDH particles can be either in 
their native layered state, or they can be partially or completely exfoliated to isolate the individual layers and thereby augment the interfacial contact area between inorganic and matrix. Most LDH/polymer nanocomposites ${ }^{11}$ have been prepared by melt or solvent blending processes using pre-formed polymers, ${ }^{6-10,} 12-14$ or by in situ polymerization using LDH modified with surfactant, ${ }^{15-18}$ initiator, ${ }^{19}, 20$ monomer, ${ }^{21}$ or controlling agents. ${ }^{22}$ While waterborne processes are preferable for coating applications, the few reports which produced LDH/polymer nanocomposites in aqueous medium by using emulsion ${ }^{16-18,20}$ or suspension ${ }^{15}$ polymerization typically required surfactant, which impacts film performance, and were not able to control particle morphology. Recent developments in controlled radical polymerization in aqueous dispersed systems, however, offer promise for overcoming these limitations. ${ }^{23,24}$

We recently reported the synthesis of $\mathrm{LDH} /$ polymer nanocomposite particles ${ }^{25}$ using a reversible addition-fragmentation chain transfer (RAFT)-mediated emulsion polymerization technique pioneered by Hawkett and co-workers. ${ }^{26}$ Coined RAFT-assisted encapsulating emulsion polymerization (REEP) ${ }^{26}$ the technique uses short, statistical copolymers synthesized by RAFT polymerization to stabilize nanoparticles in aqueous solution, and provide reactivatable groups from which polymer growth can occur in a subsequent emulsion polymerization step. The first report of nanocomposites made by this approach achieved complete encapsulation of titanium dioxide nanoparticles in a shell polymerized from a methyl methacrylate (MMA)/n-butyl acrylate (BA) 7:3 (mass/mass) feed, ${ }^{26}$ and it has since been used to synthesise nanocomposite particles from spherical or near-spherical nanoparticles ${ }^{26-33}$ and vesicles, ${ }^{34,}, 35$ and from anisotropic nanoparticles including gibbsite, ${ }^{36}$ montmorillonite, ${ }^{37}$ carbon nanotubes, ${ }^{38,}, 39$ and graphene oxide. $^{40}$ In our preliminary work on LDH nanocomposites by REEP, the morphology was primarily the so-called "sandwich" morphology, in which each inorganic platelet displays polymer growth on both its faces, while its edges show a strong preference to remain polymer- 
free. Platelets are therefore "sandwiched" between polymer nodes. We expect this was the thermodynamically preferred configuration given that the polymer shell formed from MA/BA 80:20 (mass/mass) would have been relatively mobile at the polymerization temperature.

Nancomposite morphologies depend on the interplay between thermodynamics and kinetics, ${ }^{41}$ and are hard to predict in REEP systems. In a nanocomposite particle comprising polar inorganic and hydrophobic polymer, a minimization of surface energy would logically place the inorganic at the polymer/water interface. ${ }^{42,}{ }^{43}$ If the inorganic and polymer surface energies differ less, however, equilibrium structures in which inorganic particles are more enclosed by polymer become envisagable. ${ }^{44}$ For kinetic reasons, non-equilibrium structures may also predominate. ${ }^{45}$ Encapsulation of anisotropic particles by REEP has only been reported using high $T_{\mathrm{g}}$ monomer compositions, ${ }^{36-40}$ where the morphology is considered a non-equilibrium state kinetically trapped by the hard polymer shell. ${ }^{46}$ In Ali et al., moving to a lower $T_{\mathrm{g}}$ polymer indeed gave armored structures, but the polymer was also more hydrophobic, meaning that higher mobility and higher surface energy may have both contributed to non-encapsulation. ${ }^{36}$ The influence of polymer hydrophobicity and $T_{\mathrm{g}}$, and other factors like nanofiller characteristics and macroRAFT agent nature, are therefore difficult to isolate based on REEP literature.

The Heuts group recently synthesized clay/polymer nanocomposite particles using an atomtransfer radical polymerization (ATRP)-mediated emulsion polymerization technique (which closely resembles the REEP process), raising further questions over the parameters affecting nanocomposite morphology. ${ }^{47}$ A surprising "muffin-like" morphology, in which the growing polymer formed a truncated sphere on only one face of each inorganic particle, was systematically obtained for monomer feeds of MMA/BA $=10: 1$ (mass/mass), despite the analogous REEP system giving full encapsulation. ${ }^{36}$ Although the monomer feed produced polymer with $T_{\mathrm{g}}$ above the polymerization temperature, it appears that rearrangement to minimize 
surface energy was somehow possible in the ATRP system. The reason behind this contradiction remains unanswered, although the authors recently reported that feeding a crosslinker prior to the normal monomer feed provided access to the encapsulated morphology in their ATRP system, ${ }^{46}$ suggesting that chain mobility does indeed play some role.

The factors governing nanocomposite morphology are therefore still not completely understood. In addition, film-forming polymer compositions have received much less attention than non-filmforming compositions, presumably due to the high mobility of the growing polymer shell favouring morphologies other than the preferred encapsulated morphology. Guided by our overall vision of fully controlling nanoparticle orientation in nanocomposite films, the present work explores the effect of macroRAFT agent molar mass, composition, and concentration on the morphology of film-forming LDH nanocomposites synthesized by starved-feed RAFT-mediated emulsion polymerization. We demonstrate the effect of free macroRAFT agent concentration on the prevalence of secondary nucleation, and highlight the role that the reactivatable RAFT function plays in determining the morphology of the resulting nanocomposite particles.

\section{Experimental section}

\section{Materials}

Unless otherwise specified, all chemicals were reagent grade purchased from Sigma-Aldrich and used as received. Monomers were de-inhibited prior to polymerization by passage through a column of basic alumina. Deuterated NMR solvents $\left(\mathrm{CDCl}_{3}, \mathrm{~d}_{6}\right.$-DMSO) were purchased from Cambridge Isotope Laboratories. $\mathrm{Mg}\left(\mathrm{NO}_{3}\right)_{2} \cdot 6 \mathrm{H}_{2} \mathrm{O}$ (analytical grade, Acros Organics) and $\mathrm{Al}\left(\mathrm{NO}_{3}\right)_{3} \cdot 9 \mathrm{H}_{2} \mathrm{O}$ (analytical grade, Merck) were used for LDH synthesis. 


\section{Analyses}

Nuclear magnetic resonance (NMR) spectroscopy was performed using a Bruker DRX 300S. Size exclusion chromatography (SEC) was performed using a Viscotek TDA305 equipped with three columns from Malvern Instruments [T6000 M General Mixed Org $(300 \times 8 \mathrm{~mm})]$ and RI and UV detectors. Measurements were carried out at $40{ }^{\circ} \mathrm{C}$ at a flow rate of $1 \mathrm{~mL} \mathrm{~min}^{-1}$ using toluene as a flow rate marker. Molar mass characteristics of the methylated polymers (see Syntheses section for details) were determined from the RI signals using a calibration curve based on polystyrene (PSt) standards from Polymer Laboratories. X-ray diffraction (XRD) was performed on a PANalyticalX'Pert Pro diffractometer equipped with an X'Celerator Scientific detector and a $\mathrm{Cu}$ anticathode $(\mathrm{K} \alpha 1 / \mathrm{K} \alpha 2)$. The diffracted beam was detected over a range of $3-$ $70^{\circ}(2 \theta)$ with a step size of $0.0167^{\circ}$ and a counting time of $350 \mathrm{~s}$ per step. UV/visible spectroscopy of the supernatant solutions in the macroRAFT adsorption study was conducted with a Shimadzu UV-visible spectrometer in the spectral window from $400 \mathrm{~nm}$ to $250 \mathrm{~nm}$. A Nano ZS (Malvern) device was used for dynamic light scattering (DLS) and electrophoretic mobility measurements in accordance with our previously published procedures. ${ }^{48}$ Transmission electron microscopy (TEM) was performed at $80 \mathrm{kV}$ with a Philips CM 120 microscope (Centre Technologique des Microstructures (CT $\mu$ ), platform of the Claude Bernard Lyon 1 University, Villeurbanne, France). Diluted samples (ca. $1 \mathrm{mg} \mathrm{mL}^{-1}$ ) were dropped onto a carbon-coated copper grid and dried in air. CryoTEM observations were carried out on the same instrument. A $6 \mu \mathrm{L}$ drop of the sample solution (at ca. $20 \mathrm{mg} \mathrm{mL}^{-1}$ ) was placed on a plasma-treated lacy carbon grid, and plunged into liquid ethane using a pneumatic sample preparation apparatus built inhouse (CT $\mu$, Claude Bernard Lyon 1 University). The frozen grids were transferred to a liquidnitrogen-cooled specimen holder and observed at $120 \mathrm{kV}$. 


\section{Syntheses}

$\mathrm{Mg}_{3} \mathrm{Al}-\mathrm{LDH}$

LDH was prepared by flash co-precipitation followed by hydrothermal treatment. ${ }^{49,} 50$ $\mathrm{Mg}\left(\mathrm{NO}_{3}\right)_{2} \cdot 6 \mathrm{H}_{2} 0(19.2 \mathrm{~g}, 75 \mathrm{mmol})$ and $\mathrm{Al}\left(\mathrm{NO}_{3}\right)_{3} .9 \mathrm{H}_{2} \mathrm{O}(9.4 \mathrm{~g}, 25 \mathrm{mmol})$ were dissolved in water $(1.0 \mathrm{~L})$ to give a $0.1 \mathrm{M}$ solution in metal ions. This solution was rapidly added to a vigorouslystirred solution of $\mathrm{NaOH}(800 \mathrm{~mL}, 0.25 \mathrm{M})$ at r.t. The $\mathrm{pH}$ value of the resulting suspension was adjusted to 10.0 by adding $0.25 \mathrm{M} \mathrm{NaOH}$ (ca. $25 \mathrm{~mL}$ ) and stirring was continued for $30 \mathrm{~min}$ in an open flask. The precipitate was collected by centrifugation (4 krpm, $10 \mathrm{~min})$, and washed twice by redispersing with vigorous shaking in distilled water $(2 \mathrm{~L})$ followed by centrifugation. After the final wash, the gel was re-dispersed in water $(100 \mathrm{~mL})$ and heated in an autoclave at $150{ }^{\circ} \mathrm{C}$ for $4 \mathrm{~h}$. The resulting particles were analysed by DLS and TEM, and an aliquot was dried and analysed by XRD. The sample was stored as a colloidal suspension (ca. $32 \mathrm{~g} \mathrm{~L}^{-1}$ ) in the fridge.

\section{4-cyano-4-thiothiopropylsulfanyl pentanoic acid (CTPPA)}

A synthesis of CTPPA has been described in the literature. ${ }^{51}$ We used a procedure adapted from the original RAFT agent synthesis papers ${ }^{52,53}$ which is detailed, with NMR spectra (Fig. S1 and Fig. S2), in the Supporting Information.

${ }^{1} \mathrm{H}$ NMR $\left(300 \mathrm{MHz}, \mathrm{CDCl}_{3}\right) \delta(\mathrm{ppm}): 3.32\left(\mathrm{t}, 2 \mathrm{H}, \mathrm{HOOC}-\mathrm{CH}_{2^{-}}\right), 2.68\left(\mathrm{~m}, 2 \mathrm{H},-\mathrm{SC}(\mathrm{S}) \mathrm{S}-\mathrm{CH}_{2^{-}}\right)$, $2.59-2.34\left(\mathrm{~m}, 2 \mathrm{H}, \mathrm{HOOC}-\mathrm{CH}_{2}-\mathrm{CH}_{2}-\right), 1.88\left(\mathrm{~s}, 3 \mathrm{H},-\mathrm{C}(\mathrm{CN})\left(\mathrm{CH}_{3}\right)-\right), 1.80-1.68\left(\mathrm{~m}, 2 \mathrm{H},-\mathrm{CH}_{2^{-}}\right.$ $\left.\mathrm{CH}_{3}\right), 1.02\left(\mathrm{t}, 3 \mathrm{H},-\mathrm{CH}_{2}-\mathrm{CH}_{3}\right)$.

${ }^{13} \mathrm{C}$ NMR (75 MHz, $\left.\mathrm{CDCl}_{3}\right) \delta(\mathrm{ppm}): 216.97,177.31,119.03,46.34,38.98,33.60,29.65,24.97$, $21.40,13.60$ 


\section{MacroRAFT agents}

Using $\mathrm{P}\left(\mathrm{AA}_{17.5}\right.$-co- $\left.\mathrm{BA}_{17.5}\right)-\mathrm{R}$ as a representative example, acrylic acid (AA, $\left.2.47 \mathrm{~mL}, 36.0 \mathrm{mmol}\right)$ and $n$-butyl acrylate (BA, $5.16 \mathrm{~mL}, 36.0 \mathrm{mmol})$ as monomers, CTPPA $(0.400 \mathrm{~g}, 1.44 \mathrm{mmol})$ as RAFT agent, ACPA $(0.081 \mathrm{~g}, 0.288 \mathrm{mmol})$ as initiator, and 1,3,5-trioxane $(0.130 \mathrm{~g}, 1.44 \mathrm{mmol})$ as internal standard for NMR analysis were dissolved in dioxane $(12.0 \mathrm{~mL})$ to give [monomer]:[RAFT]:[initiator] $=50: 1: 0.2$ and $[$ monomer $]=6.0 \mathrm{M}$. The solution was cooled to 0 ${ }^{\circ} \mathrm{C}$ and degassed with nitrogen bubbling for 30 minutes, then placed in an oil bath at $60{ }^{\circ} \mathrm{C}$. Samples were taken periodically using a nitrogen-purged syringe, dissolved in $\mathrm{d}_{6}$-DMSO, and analyzed immediately by ${ }^{1} \mathrm{H}$ NMR spectroscopy to determine the conversion by comparing the integral of the 1,3,5-trioxane peak to that of the vinylic protons of the monomers. When the conversion reached $70 \%$, corresponding to a degree of polymerization (DP) of 35 , the solution was quenched in an ice bath. The resulting polymer was purified by three precipitations in cold diethyl ether, with redissolution in acetone between each precipitation. The final polymer was dried overnight in a vacuum oven to give the product as a yellow solid, which was analysed by ${ }^{1} \mathrm{H}$ NMR spectroscopy and SEC. Prior to SEC analysis, a sample of polymer $(20 \mathrm{mg})$ was dissolved in THF/ $\mathrm{H}_{2} \mathrm{O}(90 / 10 \mathrm{v} / \mathrm{v}, 10 \mathrm{~mL})$ and methylated using tri(methylsilyl)diazomethane according to literature procedure, ${ }^{54}$ before drying and redissolving in THF. $\mathrm{P}\left(\mathrm{AA}_{23.3}-c 0-\mathrm{BA}_{11.7}\right)-\mathrm{R}$ was prepared similarly, but with an adjusted ratio of AA $(3.29 \mathrm{~mL}, 48.0 \mathrm{mmol})$ and BA (3.44 $\mathrm{mL}, 24.0 \mathrm{mmol}$ ). The two shorter macroRAFT agents (with DP 15) were prepared by increasing the CTPPA and initiator concentrations to give [monomer]:[RAFT]:[initiator] $=21.4: 1: 0.2$ and $[$ monomer $]=6.0 \mathrm{M}$ with appropriate AA/BA ratios. Polymerizations were again stopped at $70 \%$ conversion. 


\section{MacroRAFT agent adsorption on $L D H$}

Using $\mathrm{P}\left(\mathrm{AA}_{17.5}-\mathrm{co}-\mathrm{BA}_{17.5}\right)-\mathrm{R}$ as a representative example, a stock solution of macroRAFT agent was prepared by carefully adding $\mathrm{NaOH}\left(1.0 \mathrm{~mol} \mathrm{~L}^{-1}, 2.97 \mathrm{~mL}\right)$ to a dispersion of macroRAFT agent $\left(0.605 \mathrm{~g}, 1.61 \times 10^{-4} \mathrm{~mol}\right)$ in water $(9.49 \mathrm{~mL})$ until full dissolution and a $\mathrm{pH}$ value of 8.0 were achieved. The molar extinction coefficient at $310 \mathrm{~nm}$ was then determined by UV-visible spectroscopy from four solutions prepared at concentrations ranging from $1.12 \times 10^{-5} \mathrm{M}$ to $4.41 \mathrm{x}$ $10^{-5} \mathrm{M}$, giving $\varepsilon_{310 \mathrm{~nm}}=12591 \mathrm{M}^{-1} \mathrm{~cm}^{-1}$. A series of 8 macroRAFT agent solutions (all $2.21 \mathrm{~mL}$ ) with concentrations ranging from $0.77 \mathrm{mmol} \mathrm{L}^{-1}\left(2.89 \mathrm{~g} \mathrm{~L}^{-1}\right)$ to $5.44 \mathrm{mmol} \mathrm{L}^{-1}\left(20.51 \mathrm{~g} \mathrm{~L}^{-1}\right)$ were prepared by appropriate dilutions of the stock solution. The solutions were vigorously stirred, and an aliquot $(2.79 \mathrm{~mL})$ of $\mathrm{LDH}$ stock suspension $\left(35.8 \mathrm{~g} \mathrm{~L}^{-1}, \mathrm{pH}\right.$ value adjusted to 8.0 using $1 \mathrm{M}$ $\mathrm{HCl}$ just prior to use) was added to each in one portion. Stirring was continued for $5 \mathrm{~min}$, followed by $5 \mathrm{~min}$ of ultrasonic treatment (to redisperse any particles which stuck to the vial wall at the level of the meniscus), before centrifuging at $50 \mathrm{krpm}$ for $60 \mathrm{~min}$. The supernatants were recovered and analyzed by UV-visible spectroscopy (after appropriate dilutions to maintain absorbances below 1.0) to determine the concentration of the $\mathrm{P}\left(\mathrm{AA}_{17.5}-\mathrm{co}-\mathrm{BA}_{17.5}\right)-\mathrm{R}$ remaining in solution (denoted [macroRAFT] $]_{\text {free }}$ ) based on the absorbance at $310 \mathrm{~nm}$. The amount of $\mathrm{P}\left(\mathrm{AA}_{17.5^{-}}\right.$ co-BA $\left.{ }_{17.5}\right)-\mathrm{R}$ adsorbed on the LDH surface (denoted [macroRAFT $]_{\mathrm{ads}}$ ) in each sample was calculated by subtracting [macroRAFT] free from the total concentration of the macroRAFT agent present in that solution. Concentrations were determined by weighing all solutions (rather than relying on pipetted volumes) for greater accuracy.

\section{Starved-feed emulsion polymerizations}

Using $\mathrm{P}\left(\mathrm{AA}_{17.5}-c o-\mathrm{BA}_{17.5}\right)-\mathrm{R}$ as a representative example, a stock solution of macroRAFT agent (43.1 $\left.\mathrm{mg} \mathrm{mL}^{-1}, 11.6 \mathrm{mM}, \mathrm{pH}=8.0\right)$ at $\mathrm{pH}$ value 8.0 was prepared as described in the preceding 
paragraph. LDH suspension $\left(6.64 \mathrm{~mL}, 36.1 \mathrm{~g} \mathrm{~L}^{-1}, \mathrm{pH}=8.0\right)$ was added in one portion to a stirred aliquot of the macroRAFT agent solution $\left(3.34 \mathrm{~mL}, 5.94 \times 10^{-5} \mathrm{~mol}, 1\right.$ eq.) and the mixture was subjected to ultrasound for $10 \mathrm{~min}$. At this point, DLS was performed to confirm that the LDH particle size distribution closely resembled that of the starting LDH suspension. A solution of ACPA ( $8.33 \mathrm{mg}, 2.97 \times 10^{-5} \mathrm{~mol}, 0.5$ eq.) dissolved in water and adjusted to $\mathrm{pH}=8.0 \mathrm{using}$ $\mathrm{NaOH}$ (solution volume $0.329 \mathrm{~mL}$ ) was added, followed by water $(3.38 \mathrm{~mL}$ ) to give $[$ macroRAFT $]=12.0 \mathrm{~g} \mathrm{~L}^{-1}(3.22 \mathrm{mM}),[\mathrm{LDH}]=20.0 \mathrm{~g} \mathrm{~L}^{-1}$, and a total volume of $12.0 \mathrm{~mL} . \mathrm{A}$ portion of the solution $(2.0 \mathrm{~mL})$ was removed and dried in a pre-weighed aluminium pan at $50{ }^{\circ} \mathrm{C}$ to give the initial solids content by gravimetry. The remaining solution was transferred to a 25 $\mathrm{mL}$ round-bottom flask fitted with a magnetic stir bar and a rubber septum, and was degassed by nitrogen bubbling for $15 \mathrm{~min}$. In parallel, the monomer mixture (methyl acrylate (MA)/BA 80/20 mass/mass, ca. $1 \mathrm{~mL}$ ) was degassed separately for $15 \mathrm{~min}$ in a vial capped with a septum. The round bottom flask was accurately weighed, and then placed in an oil bath at $70{ }^{\circ} \mathrm{C}$. Injection of the monomer solution was immediately commenced by taking up the degassed monomer solution in a $1 \mathrm{~mL}$ nitrogen-purged syringe fitted with a long needle, inserting the needle through the septum in the macroRAFT/LDH solution such that it was touching the flask wall just above the level of the liquid, quickly placing the syringe in a Perfusor ${ }^{\circledR}$ compact syringe pump, and starting the injection at a rate corresponding to $0.3 \mathrm{~g} \mathrm{~h}^{-1}$. After $2.0 \mathrm{~h}$, the monomer injection was ceased, and the reaction mixture was stirred for a further $2 \mathrm{~h}$. Samples (ca. $0.75 \mathrm{~mL}$ ) were taken every hour using pre-weighed $1 \mathrm{~mL}$ syringes, the mass of each removed samples was recorded, and a portion of each sample was analysed by DLS. The remaining portion was dried and weighed to determine conversions gravimetrically. CryoTEM was performed on a portion of the final solution (and in some cases on the intermediate solutions). For SEC analysis, a portion of dried sample (ca. $20 \mathrm{mg}$ ) was stirred overnight in THF (5 mL) containing conc. $\mathrm{HCl}$ (ca. 2 eq. relative 
to $\mathrm{COOH}$ groups), sonicated for $10 \mathrm{~min}$, filtered using a $0.45 \mu \mathrm{m}$ PTFE filter, then the filtrate was directly methylated according to the same procedure used for the macroRAFT agent syntheses.

\section{Removal of the RAFT function}

Based on literature precedent, ${ }^{55} \mathrm{P}\left(\mathrm{AA}_{17.5}-c o-\mathrm{BA}_{17.5}\right)-\mathrm{R}\left(0.50 \mathrm{~g}, 1.33 \times 10^{-4} \mathrm{~mol}, 1\right.$ eq. $)$, AIBN ( $0.436 \mathrm{~g}, 2.65 \times 10^{-3} \mathrm{~mol}, 20$ eq.), and lauroyl peroxide (0.106 g, $2.65 \times 10^{-4} \mathrm{~mol}, 2$ eq.) were dissolved in dioxane $(10.0 \mathrm{~mL})$ in a round-bottom flask fitted with a magnetic stir bar and a septum. The solution was degassed by nitrogen bubbling for $30 \mathrm{~min}$, and the flask was placed in an oil bath at $80{ }^{\circ} \mathrm{C}$. After $4 \mathrm{~h}$, the solution was cooled to room temperature, and the pure polymer was isolated in an identical fashion to that described for the macroRAFT agent syntheses.

\section{Results and discussion}

The objective of the present work was to control the morphology of film-forming nanocomposite latexes containing LDH nanoparticles. Full conversion and minimization of secondary nucleation were prerequisites. Our overall approach based on the REEP technique is shown in Scheme 1. It should be noted that since the removal of the RAFT group was also explored, not all systems strictly qualify as REEP processes. 

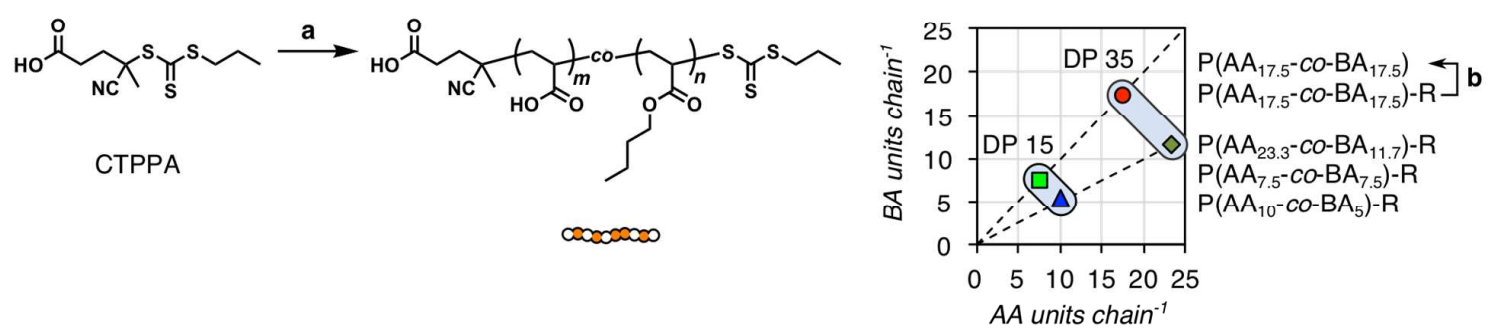

Adsorption onto LDH

Starved-feed emulsion polymerization
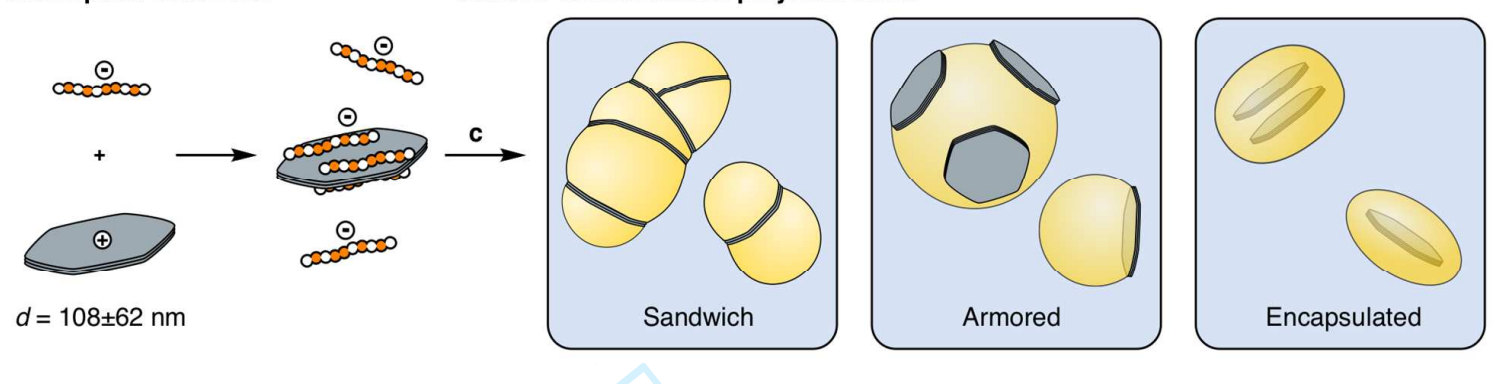

Scheme 1. Overall process for the encapsulation of $\mathrm{LDH}$ particles in polymer latexes using RAFT-mediated emulsion polymerization; a) Acrylic acid (AA)/n-butyl acrylate (BA), dioxane, 4,4'-azobis(4-cyanopentanoic acid) (ACPA), $60^{\circ} \mathrm{C}$; b) Azobisisobutyronitrile (AIBN), lauroyl peroxide, dioxane, $80{ }^{\circ} \mathrm{C}, 4 \mathrm{~h}$; $\left.\mathrm{c}\right)$ Water $(\mathrm{pH}$ value $=8.0)$, ACPA, monomer feed (most frequently methyl acrylate (MA)/BA), $70{ }^{\circ} \mathrm{C}, 4 \mathrm{~h}$.

\section{MacroRAFT agent and LDH syntheses}

The purpose of the macroRAFT agent in REEP systems is purportedly two-fold: to provide a reactivatable group which encourages polymerization to proceed from the particle surface, and to stabilize the resulting composite particles. Statistical copolymers of charged monomers and hydrophobic (non-charged) monomers have proven to be suitable candidates for this purpose. ${ }^{36,37}$ The charged units are responsible for electrostatic adsorption to the charged inorganic surface and colloidal stability of the hydrophobic shell through electrostatic repulsion, and the hydrophobic 
units encourage hydrophobic interactions between adsorbed chains, monomer, and growing hydrophobic polymer.

The total number and the ratio of hydrophilic to hydrophobic monomer units in the macroRAFT agent have both proven to influence the final latex characteristics. In their encapsulation of gibbsite using a MMA/BA 10:1 (mass/mass) feed, a series of three macroRAFT agents with 10 AA units and either 2.5, 5, or 7.5 BA units was explored by Hawkett and co-workers. ${ }^{36}$ The first gave latex particle agglomeration, the second gave excellent encapsulation with no free latex particle formation, and the third gave encapsulation but with some free particle formation. In explaining the first case, the authors proposed that the hydrophilic chains were more water soluble and less inclined to adsorb on the inorganic surface, giving lower colloidal stability. In the third case, the lower water solubility of this more hydrophobic macroRAFT agent meant that chain extension with the hydrophobic monomer during emulsion polymerization resulted in earlier onset of a self-assembly process in the aqueous phase. It is important to note that not all of the macroRAFT agent in REEP systems is adsorbed on the inorganic surface; some remains free in solution, and can potentially be recruited to the growing composite particles or undergo chain extension in solution to form secondary (nanoparticle-free) particles. This work highlights the fine influence of macroRAFT agent composition on latex properties.

Four macroRAFT agents $-\mathrm{P}\left(\mathrm{AA}_{10}-c o-\mathrm{BA}_{5}\right)-\mathrm{R}, \mathrm{P}\left(\mathrm{AA}_{23.3}-c o-\mathrm{BA}_{11.7}\right)-\mathrm{R}, \mathrm{P}\left(\mathrm{AA}_{7.5}-c o-\mathrm{BA}_{7.5}\right)-\mathrm{R}$ and $\mathrm{P}\left(\mathrm{AA}_{17.5}-\mathrm{co}-\mathrm{BA}_{17.5}\right)-\mathrm{R}$ - were therefore synthesized in the present work by copolymerizing AA and BA using the RAFT agent CTPPA (Scheme 1). The first and second displayed AA/BA $=2: 1$ and will be referred to as the "more hydrophilic" pair, and the third and fourth displayed AA/BA $=1: 1$ to comprise the "more hydrophobic" pair, with the DP either 15 or 35 within each pair. The effect of both hydrophilic/hydrophobic balance and molar mass could therefore be isolated in the subsequent adsorption and emulsion polymerization experiments. Note that all four macroRAFT 
agents were completely soluble once the acid groups were deprotonated in the stock solution preparation (at ca. $43 \mathrm{~g} \mathrm{~L}^{-1}$ ). The RAFT polymerizations to attain these macroRAFT agents were well controlled, giving linear evolution of molar mass with conversion and low dispersities (example for $\mathrm{P}\left(\mathrm{AA}_{10}-c o-\mathrm{BA}_{5}\right)-\mathrm{R}$ shown in Supporting Information, Fig. S3a). SEC traces for the two DP pairs were almost perfectly overlayed, with the theoretical and measured molar masses and dispersities summarized in Table 1. As previously reported, the monomer units were incorporated at their feed proportions throughout the polymerization, indicating very similar reactivity ratios. ${ }^{36}$ All polymerizations exhibited a significant initialization period, during which RAFT agent is converted almost exclusively to single monomer adducts before any appreciable formation of longer chains. ${ }^{56,57}$ Initialization times are known to be more pronounced at low [M]:[RAFT], as was the case here. Adding the monomer to the system $60 \mathrm{~min}$ after heating had commenced produced a ca. 60 min delay in the onset of polymerization (Supporting Information, Fig. S3b), confirming that the initialization period was indeed intrinsic to the RAFT mechanism. The final entry in Table 1 is a RAFT-free version of $\mathrm{P}\left(\mathrm{AA}_{17.5}-c o-\mathrm{BA}_{17.5}\right)-\mathrm{R}$, whose synthesis and purpose will be discussed in a later section.

Table 1. Charge density and molar mass characteristics (by SEC against PSt standards) of the stabilizing polymers used in this study.

\begin{tabular}{|l|l|l|l|l|}
\hline Stabilizing polymer & $\begin{array}{l}\text { Negative charge density } \\
\left(\mathbf{m m o l} \mathbf{~ g}^{\mathbf{- 1}}\right)\end{array}$ & $\begin{array}{l}\boldsymbol{M}_{\mathbf{n}, \text { theor }} \\
\left(\mathbf{k g ~ m o l}^{-\mathbf{1}}\right)\end{array}$ & $\begin{array}{l}\boldsymbol{M}_{\mathbf{n}, \mathbf{S E C}} \\
\mathbf{( k g ~ m o l}^{-\mathbf{1}} \mathbf{)}\end{array}$ & $\boldsymbol{D}$ \\
\hline $\mathrm{P}\left(\mathrm{AA}_{10}-c o-\mathrm{BA}_{5}\right)-\mathrm{R}$ & 6.65 & 1.65 & 1.49 & 1.19 \\
\hline $\mathrm{P}\left(\mathrm{AA}_{23.3}-c o-\mathrm{BA}_{11.7}\right)-\mathrm{R}$ & 7.08 & 3.43 & 3.78 & 1.18 \\
\hline $\mathrm{P}\left(\mathrm{AA}_{7.5}-c o-\mathrm{BA}_{7.5}\right)-\mathrm{R}$ & 4.57 & 1.85 & 1.87 & 1.19 \\
\hline $\mathrm{P}\left(\mathrm{AA}_{17.5}-c o-\mathrm{BA}_{17.5}\right)-\mathrm{R}$ & 4.91 & 3.76 & 3.80 & 1.19 \\
\hline
\end{tabular}




\begin{tabular}{|l|l|l|l|l|}
\hline $\mathrm{P}\left(\mathrm{AA}_{17.5}-\mathrm{co}-\mathrm{BA}_{17.5}\right)$ & 4.75 & 3.68 & 3.95 & 1.20 \\
\hline
\end{tabular}

${ }^{\mathrm{a}}$ Calculated by dividing the theoretical number of carboxylate groups per chain by the theoretical molar mass.

The $\mathrm{LDH}$ particles with abbreviated composition $\mathrm{Mg}_{3} \mathrm{Al}-\mathrm{CO}_{3}$ (where $\mathrm{M}^{3+} / \mathrm{M}^{2+}=0.33$ falls within the range of 0.1 to 0.5 typically used for synthetic LDH), ${ }^{5}$ were synthesized using flash precipitation followed by hydrothermal treatment. ${ }^{50}$ Performing the coprecipitation in air produces LDH containing the carbonate anion, which prevents further anionic exchanges in the interlamellar spaces. The resulting particles displayed an intensity average particle size of $108 \mathrm{~nm}$ $(\mathrm{s} . \mathrm{d}=62 \mathrm{~nm})$ by DLS (Supporting Information, Fig. S4a). Powder XRD analysis showed diffraction lines $(00 l),(012),(110)$ and (113) characteristic of LDH (Supporting Information, Fig. $\mathrm{S} 4 \mathrm{~b}$ ), with the $00 l$ diffraction line positions indicating an interlayer distance of $0.79 \mathrm{~nm}$ which corresponds to the expected carbonate LDH phase. ${ }^{25}$

\section{MacroRAFT agent adsorption onto LDH}

The first step in the encapsulation process is the adsorption of macroRAFT agent on the LDH particles. The adsorption capacity of the LDH, and the partitioning of macroRAFT between the inorganic particles and the solution, were therefore of great interest in determining the quantities of macroRAFT agent and LDH required for the subsequent polymerizations.

To study the adsorption behavior, a series of solutions was prepared in which the LDH concentration was held constant at $20 \mathrm{~g} \mathrm{~L}^{-1}$ and the macroRAFT concentration was varied over the range of ca. 1 to ca. $16 \mathrm{~g} \mathrm{~L}^{-1}$. The resulting adsorption isotherms are shown in Fig. 1a. 

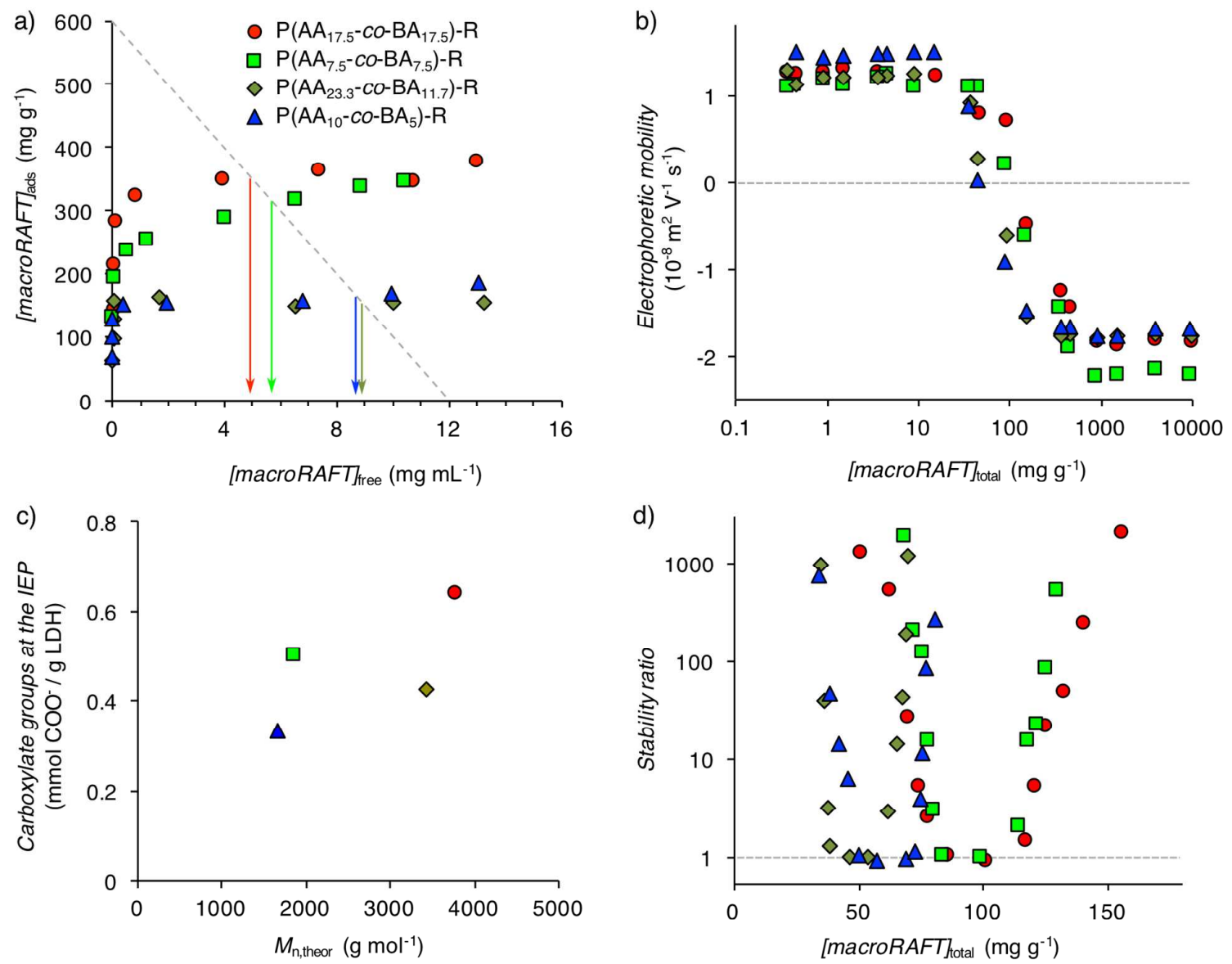

Figure 1. a) Adsorption isotherms for the four macroRAFT agents used in this work; $[\mathrm{LDH}]=20$ $\mathrm{g} \mathrm{L}^{-1}, \mathrm{pH}$ value 8.0. The intersections of the grey dotted line (imposed by [macroRAFT] $]_{\text {total }}=12$ $\mathrm{mg} \mathrm{mL} \mathrm{m}^{-1},[\mathrm{LDH}]=20 \mathrm{mg} \mathrm{mL}^{-1}$ ) with each of the four isotherms correspond to the distribution of macroRAFT agent (adsorbed vs. free) in the emulsion polymerization systems $\mathrm{L}_{4}-\mathrm{L}_{11}$ (Table 2). The vertical arrows explicitly show the $[\text { macroRAFT }]_{\text {free }}$ for each. b) Electrophoretic mobility in the presence of different concentrations of the four macroRAFT agents; [LDH] $=10 \mathrm{mg} \mathrm{L}^{-1}$. c) Relative amount of carboxylate groups required to reach the IEP in b). d) Stability ratio of LDH particles at different macroRAFT agent concentrations. The legend in a) applies to all four plots. 
The adsorption series exhibit relatively sharp step-like profiles, indicative of strong adsorption, rather than gradual increases in both free and adsorbed polymer that are characteristic of weaker Langmuir-type adsorption behaviour. ${ }^{28}$ At low macroRAFT concentrations, marked by the nearvertical portions of the curves, almost all macroRAFT agent $(>98 \%)$ was adsorbed in all four cases (Fig. 1a). The gradient of this portion of the curve reflects the affinity of the polymer for the inorganic surface, ${ }^{27}$ and is particularly high in this case due to the permanent and high charge density on the LDH. As the macroRAFT agent concentration increased, there was a marked difference in the behavior of the macroRAFT agents depending on their AA/BA ratio. $\mathrm{P}\left(\mathrm{AA}_{23.3^{-}}\right.$ co- $\left.\mathrm{BA}_{11.7}\right)-\mathrm{R}$ and $\mathrm{P}\left(\mathrm{AA}_{10}-c o-\mathrm{BA}_{5}\right)-\mathrm{R}$ both exhibit adsorption capacities of ca. $150 \mathrm{mg} \mathrm{g}^{-1}$, defined as the intersection of a linear fit of the last 5 data points with the y-axis. Essentially all incremental macroRAFT agent above this concentration remained free in solution. The very close agreement between the two curves shows that the differing molar masses had a negligible effect

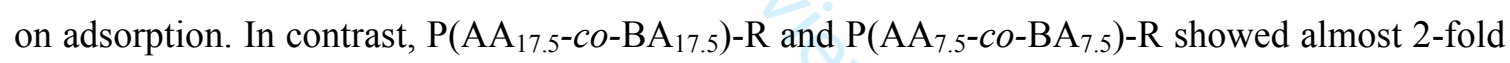
higher adsorption capacities (ca. $300 \mathrm{mg} \mathrm{g}^{-1}$ and ca. $250 \mathrm{mg} \mathrm{g}^{-1}$ respectively), and continually rising adsorption over the tested range. Slightly higher adsorption was expected for the hydrophobic pair due to their lower charge densities (Table 1), but this does not fully account for the ca. 2-fold difference in adsorption. Taken together, these results confirm the role of the hydrophobic BA units in encouraging higher and continually increasing adsorption. ${ }^{58}$ Polyelectrolytes of lower line charge density, such as the BA-rich pair here, have indeed been shown in literature to adsorb in higher amounts due to the decreased electrostatic repulsion between the adsorbed molecules. ${ }^{59}$

Two additional studies with $[\mathrm{LDH}]=10 \mathrm{mg} \mathrm{L}^{-1}-2000$-fold more dilute than in Fig. 1a-were performed to probe the adsorption of the four macroRAFT agents using electrophoresis and DLS (Fig $1 \mathrm{~b}-\mathrm{d}) .^{48}$ This was intended to give complementary information on the adsorption behavior, 
namely the surface charge and the aggregation rate over a large range of overall macroRAFT concentrations.

For all four macroRAFT agents, the electrophoretic mobilities of the LDH particles began positive, declined through zero (defined as the isoelectric point, IEP) to more negative values before stabilizing at very high macroRAFT agent concentrations (Fig. 1b). The charge inversion originates from hydrophobic interactions between the polyelectrolyte chains, entropy gain due to the release of solvent molecules, and ion-ion correlations. ${ }^{59}$ These measurements revealed the effect of both AA/BA ratio and molar mass on the quantity of macroRAFT agent required to neutralize the LDH surface charge. $\mathrm{P}\left(\mathrm{AA}_{10}-c o-\mathrm{BA}_{5}\right)-\mathrm{R}$ and $\mathrm{P}\left(\mathrm{AA}_{23.3}-c o-\mathrm{BA}_{11.7}\right)-\mathrm{R}$ exhibited IEPs of ca. $50 \mathrm{mg} \mathrm{g}^{-1}$ and $60 \mathrm{mg} \mathrm{g}^{-1}$ respectively. In contrast, $\mathrm{P}\left(\mathrm{AA}_{7.5}-\mathrm{co}-\mathrm{BA}_{7.5}\right)-\mathrm{R}$ and $\mathrm{P}\left(\mathrm{AA}_{17.5}-\mathrm{co}-\right.$ $\mathrm{BA}_{17.5}$ )- $\mathrm{R}$ gave IEPs over 2-fold higher at $110 \mathrm{mg} \mathrm{g}^{-1}$ and $130 \mathrm{mg} \mathrm{g}^{-1}$ respectively, which is not entirely attributable to differing charge densities. The charge density of $\mathrm{P}\left(\mathrm{AA}_{7.5}-\mathrm{co}-\mathrm{BA}_{7.5}\right)-\mathrm{R}$ was only $31 \%$ lower than that of $\mathrm{P}\left(\mathrm{AA}_{10}-\mathrm{co}-\mathrm{BA}\right)-\mathrm{R}$, yet its IEP was over 2-fold higher. The higher molar mass pair showed a comparable difference. When the macroRAFT agents were richer in BA, significantly more polymer was required to neutralize the LDH surface charge than one would expect based on the number of carboxylate groups they contribute. A similar, less pronounced, effect was observed when the molar mass was increased while keeping the AA/BA ratio constant. For both $\mathrm{AA} / \mathrm{BA}$ ratios, more of the higher molar mass polymer was required to neutralize the LDH surface charge. The effect of both AA/BA ratio and molar mass on IEP is best summarized in Fig. 1c, which shows the number of macroRAFT-contributed carboxylate units present at the IEP for each macroRAFT agent. If the neutralization of LDH surface charge were simply a function of the total carboxylate groups added to the system, then all four macroRAFT agents would fall on a horizontal line. Instead, the two BA-rich macroRAFT agents require 50\% more carboxylate groups to reach the IEP compared to their BA-poor counterparts. 
The two higher molar mass macroRAFT agents require $27 \%$ more carboxylate groups to reach the IEP than their lower molar mass counterparts. Lower charge density and higher molar mass are known to favour the formation of loops and tails in adsorbed polyelectrolytes, which explains why the effectiveness of the carboxylate units to neutralize the LDH surface charge was significantly reduced with increasing BA content, and moderately reduced with higher molar mass in the macroRAFT agents used here.

Beyond the IEPs, electrophoretic mobilities plateau beyond ca. $150 \mathrm{mg} \mathrm{g}^{-1}$ for the $\mathrm{AA} / \mathrm{BA}=2$ pair and at significantly higher concentrations for the AA/BA $=1$ pair, which almost perfectly match the plateau values observed in Fig. 1a. The adsorption behavior can therefore be considered relatively independent of the LDH concentration, since this differed 2000-fold between the two experimental procedures.

Finally, we used time-resolved dynamic light scattering (DLS) to measure the rate at which the hydrodynamic radius $\left(R_{\mathrm{h}}\right)$ of the $\mathrm{LDH}$ particles increased immediately after mixing with macroRAFT agent, which is a measure of aggregation rate. The colloidal stability was expressed in terms of the stability ratio, $W$, shown in Fig. $1 \mathrm{~d}$ for all four macroRAFT agents. $W$ is defined as the initial rate of aggregation at the IEP divided by the initial rate of aggregation for the particular sample. The absence of surface charge at the IEP means that the rate of aggregation at the IEP is higher than at any other macroRAFT agent concentration. Stability ratios are therefore greater than or equal to 1 , with higher values corresponding to higher stability. ${ }^{60}$

The stability ratio trends across the four macroRAFT agents can again be grouped based on the AA/BA ratio. The two macroRAFT agents with $\mathrm{AA} / \mathrm{BA}=2$ show essentially superimposed stability ratio profiles, with stability ratios declining from very high values (at low macroRAFT concentration) to minima of 1 at macroRAFT concentrations which correspond to the IEPs shown in Fig. 1b, before rapidly increasing with further macroRAFT addition. The AA/BA $=1$ systems 
are also closely aligned, with minima corresponding to the IEPs in Fig. 1b. The stability ratios are interesting in the context of the subsequent emulsion polymerizations. Colloidal stability of the LDH particles prior to commencing the emulsion polymerization is important for ensuring latex stability, and reducing the likelihood of encapsulating many (aggregated) LDH particles within each latex particle. Polymerizations $\mathrm{L}_{4}-\mathrm{L}_{11}$ were conducted with a total macroRAFT concentration of $600 \mathrm{mg} \mathrm{g}^{-1}$, which is significantly higher than the range of data in Fig. 1d and corresponds to high stability ratios and therefore low or not even measurable aggregation rates.

\section{Starved-feed emulsion polymerizations}

Starved-feed emulsion polymerization was performed by mixing macroRAFT agent with LDH in a similar fashion to the adsorption experiments, adding initiator, then injecting monomer under starved-feed conditions. Polymerizations were performed on a $10 \mathrm{~g}$ scale, with [RAFT]:[initiator]

$=2$, and targeting solids contents of around $10 \%$ (mass $/$ mass). Having determined that the macroRAFT agent concentration strongly influences the colloidal stability of macroRAFTadsorbed $\mathrm{LDH}$, the role of macroRAFT agent concentration was the first parameter explored in the emulsion polymerizations. A summary of all latexes described in this work is presented in Table 2. 
Table 2. Latexes produced by the emulsion polymerizations performed in this work.

\begin{tabular}{|c|c|c|c|c|c|c|c|c|c|c|c|c|}
\hline Label & $\begin{array}{l}\text { Stabilizing polymer, } \\
\text { P }\end{array}$ & $\begin{array}{l}{[\mathrm{LDH}]} \\
\left(\mathrm{g} \mathrm{L}^{-1}\right)\end{array}$ & $\begin{array}{l}{[\mathbf{P}]} \\
\left(\begin{array}{ll}g & \mathbf{L}^{-1}\end{array}\right. \\
\left.\mathrm{mmol} \mathrm{L}^{-1}\right)\end{array}$ & $\begin{array}{l}{[\mathbf{P}]_{\text {free }}} \\
\left(\begin{array}{l}g \quad \mathbf{L}^{-1} \\
\mathbf{m m o l ~ L}^{-1}\end{array}\right)\end{array}$ & $\begin{array}{l}\text { Feed } \\
\text { (mass/mass) }\end{array}$ & $\begin{array}{l}\mathbf{t}^{\mathrm{a}} \\
\text { (h) }\end{array}$ & $\begin{array}{l}\mathrm{X}^{\mathrm{b}} \\
(\%)\end{array}$ & Morphology & $\begin{array}{l}M_{\mathrm{n}, \text { theor }} \\
\left(\mathrm{kg} \mathrm{mol}^{-1}\right)\end{array}$ & $\begin{array}{l}M_{\mathrm{n}, \mathrm{SEC}}{ }^{\mathrm{c}} \\
\left(\mathrm{kg} \mathrm{mol}^{-1}\right)\end{array}$ & $\boldsymbol{\theta}^{\mathbf{b}}$ & $\begin{array}{l}T_{\mathrm{g}, \mathrm{Fox}}{ }^{\mathrm{d}} \\
\left({ }^{\circ} \mathrm{C}\right)\end{array}$ \\
\hline $\mathrm{L}_{1}$ & $\mathrm{P}\left(\mathrm{AA}_{17.5}-c o-\mathrm{BA}_{17.5}\right)-\mathrm{R}$ & 6.5 & $4.3 / 1.1$ & $2.0 / 0.5$ & MA/BA 80:20 & 3 & 84 & Sandwich & - & - & - & -9 \\
\hline $\mathrm{L}_{2}$ & $\mathrm{P}\left(\mathrm{AA}_{17.5}-c o-\mathrm{BA}_{17.5}\right)-\mathrm{R}$ & 6.5 & $8.6 / 2.3$ & $6.0 / 1.6$ & MA/BA 80:20 & 3 & 88 & Sandwich & - & - & - & -9 \\
\hline $\mathrm{L}_{3}$ & $\mathrm{P}\left(\mathrm{AA}_{17.5}-c o-\mathrm{BA}_{17.5}\right)-\mathrm{R}$ & 6.5 & $17.2 / 4.6$ & $14.5 / 3.9$ & MA/BA 80:20 & 3 & 91 & Sandwich & - & - & - & -9 \\
\hline $\mathrm{L}_{4}$ & $\mathrm{P}\left(\mathrm{AA}_{\left.17.5^{-}-c o-\mathrm{BA}_{17.5}\right)-\mathrm{R}}\right.$ & 20 & $12 / 3.2$ & $5.0 / 1.3$ & MA/BA 80:20 & 4 & 101 & Sandwich & 25.3 & 21.5 & 1.7 & -9 \\
\hline $\mathrm{L}_{5}$ & $\mathrm{P}\left(\mathrm{AA}_{17.5}-c o-\mathrm{BA}_{17.5}\right)-\mathrm{R}$ & 20 & $12 / 3.2$ & $5.0 / 1.3$ & MMA/BA 90:10 & 4 & 99 & Encapsulated & - & - & - & 80 \\
\hline $\mathrm{L}_{6}$ & $\mathrm{P}\left(\mathrm{AA}_{17.5}-c o-\mathrm{BA}_{17.5}\right)-\mathrm{R}$ & 20 & $12 / 3.2$ & $5.0 / 1.3$ & MMA/BA 50:50 & 4 & 97 & Sandwich & - & - & - & 4 \\
\hline $\mathrm{L}_{7}$ & $\mathrm{P}\left(\mathrm{AA}_{17.5}-c o-\mathrm{BA}_{17.5}\right)-\mathrm{R}$ & 20 & $12 / 3.2$ & $5.0 / 1.3$ & $\begin{array}{l}\text { MA/BA/EGDA } \\
80: 17: 3\end{array}$ & 4 & 95 & Encapsulated & - & - & - & - \\
\hline $\mathrm{L}_{8}$ & $\mathrm{P}\left(\mathrm{AA}_{10}-c o-\mathrm{BA}_{5}\right)-\mathrm{R}$ & 20 & $12 / 7.3$ & $8.7 / 5.3$ & MA/BA 80:20 & 4 & - & Unstable & - & - & - & -9 \\
\hline $\mathrm{L}_{9}$ & $\mathrm{P}\left(\mathrm{AA}_{23.3}-c o-\mathrm{BA}_{11.7}\right)-\mathrm{R}$ & 20 & $12 / 3.5$ & $8.9 / 2.6$ & MA/BA 80:20 & 4 & 98 & Sandwich & - & - & - & -9 \\
\hline $\mathrm{L}_{10}$ & $\mathrm{P}\left(\mathrm{AA}_{7.5}-c o-\mathrm{BA}_{7.5}\right)-\mathrm{R}$ & 20 & $12 / 6.5$ & $5.7 / 3.1$ & MA/BA 80:20 & 4 & 101 & Encapsulated & 12.2 & 12.7 & 1.5 & -9 \\
\hline $\mathrm{L}_{11}$ & $\mathrm{P}\left(\mathrm{AA}_{17.5}-c o-\mathrm{BA}_{17.5}\right)$ & 20 & $12 / 3.2$ & $5.0 / 1.3$ & MA/BA 80:20 & 4 & 103 & Armored & - & 151 & 3.8 & -9 \\
\hline
\end{tabular}


${ }^{\mathrm{a}}$ Monomer injection was performed for the first $2 \mathrm{~h} .{ }^{\mathrm{b}}$ Values just above $100 \%$ indicate the accuracy of the conversion calculation method to within a few percentage points. ${ }^{\mathrm{c}}$ By SEC against PSt standards. ${ }^{\mathrm{d}}$ Theoretical $T_{\mathrm{g}}$ for the polymer shell calculated from the monomer feed composition and the $T_{\mathrm{g}}$ values of the pure polymers $\left(T_{\mathrm{g}, \mathrm{PMA}}=5^{\circ} \mathrm{C}, T_{\mathrm{g}, \mathrm{PMMA}}=-54^{\circ} \mathrm{C}, T_{\mathrm{g}, \mathrm{PMMA}}=106^{\circ} \mathrm{C}\right)^{61} \mathrm{using}$ the Fox equation: ${ }^{62} 1 / T_{\mathrm{g}, \mathrm{Fox}}=x_{1} / T_{\mathrm{g}, 1}+x_{2} / T_{\mathrm{g}, 2}$ where $T_{\mathrm{g}, 1}$ and $T_{\mathrm{g}, 2}$ are glass transition temperatures, and $x_{1}$ and $x_{2}$ are the mass fractions, of components 1 and 2 respectively. 
Effect of [macroRAFT] free on latex stability and secondary nucleation

The importance of the free macroRAFT agent concentration was tested by using $\mathrm{P}\left(\mathrm{AA}_{17.5}-\mathrm{co}\right.$ $\left.\mathrm{BA}_{17.5}\right)-\mathrm{R}$ adsorbed on the $\mathrm{LDH}$ at a concentration of $6.5 \mathrm{~g} \mathrm{~L}^{-1}$. This LDH concentration was higher than in our previous work to target higher solids contents at a given polymer/LDH ratio while retaining the possibility of producing anisotropic nanocomposite particles at full conversion. ${ }^{25}$ Three systems were tested containing total macroRAFT concentrations of $4.3 \mathrm{~g} \mathrm{~L}^{-1}$, 8.6 $\mathrm{g} \mathrm{L}^{-1}$, and $17.2 \mathrm{~g} \mathrm{~L}^{-1}$ using a monomer feed of MA/BA 80:20 (mass/mass). At $3 \mathrm{~h}$, the conversions were $84 \%, 88 \%$, and $91 \%$ respectively. Subsequent polymerizations were therefore extended to $4 \mathrm{~h}$ to seek full conversion. The morphologies of the resulting latexes are shown in Fig. 2.
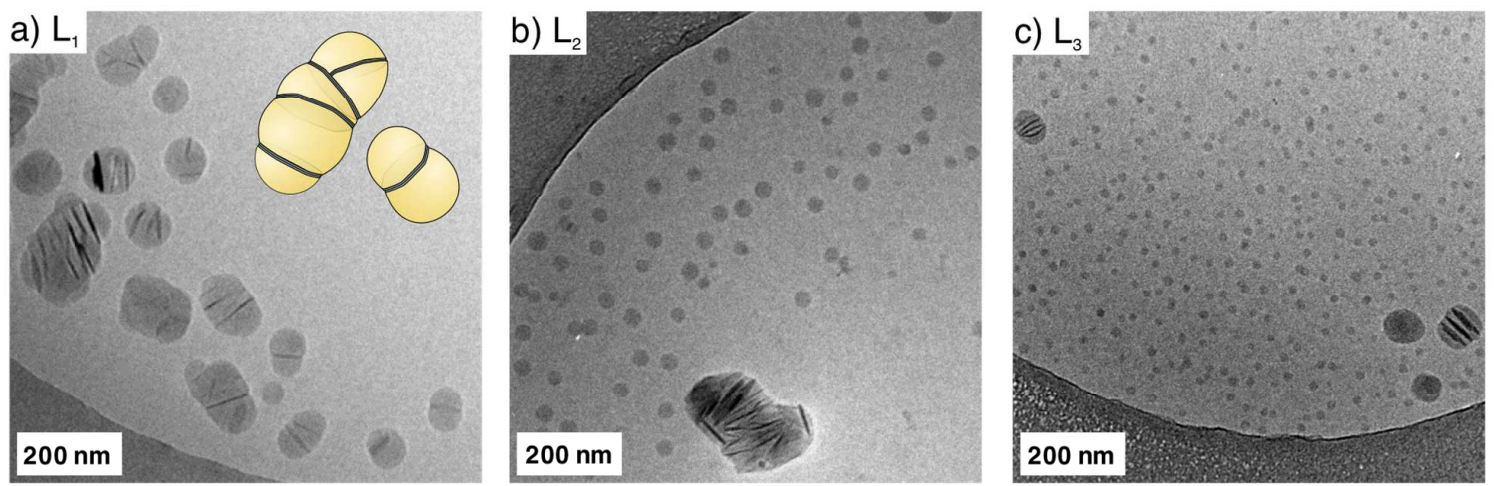

Figure 2. CryoTEM images showing final particle morphologies at $3 \mathrm{~h}$ in the emulsion polymerizations using $[\mathrm{LDH}]=6.5 \mathrm{~g} \mathrm{~L}^{-1}$, monomer $=\mathrm{MA} / \mathrm{BA}$ 80:20 (mass/mass) and $\mathrm{P}\left(\mathrm{AA}_{17.5^{-}}\right.$ co-BA 17.5$)-\mathrm{R}$ concentrations of a) $4.3 \mathrm{~g} \mathrm{~L}^{-1}\left(\mathrm{~L}_{1}\right)$, b) $8.6 \mathrm{~g} \mathrm{~L}^{-1}\left(\mathrm{~L}_{2}\right)$, and c) $17.2 \mathrm{~g} \mathrm{~L}^{-1}\left(\mathrm{~L}_{3}\right)$.

The stability of $\mathrm{L}_{1}$ was inferior to that of the other two systems, showing some sedimentation visible to the naked eye. The cryoTEM image in Fig. 2a was taken from the stable portion of the polymerization solution. This image demonstrates that almost every latex particle is associated 
with at least one LDH particle, meaning there is very little secondary nucleation. The free macroRAFT concentration of ca. $2.0 \mathrm{~g} \mathrm{~L}^{-1}$ (estimated from the adsorption isotherm in Fig. 1a) was not sufficiently high to sustain stability throughout the emulsion polymerization process. The macroRAFT polymer chains which were initially free in solution were most likely adsorbed by the growing latex particles ${ }^{26}$ rather than undergoing any free polymer particle formation in the solution. Secondary nucleation was therefore avoided, but at the expense of colloidal stability.

The higher macroRAFT concentration of $8.6 \mathrm{~g} \mathrm{~L}^{-1}$ in $\mathrm{L}_{2}$ gave a stable latex, but also encouraged some secondary particle formation, with a significant population of spherical LDH-free polymer particles with diameters around $30 \mathrm{~nm}$ evident in the cryoTEM images (Fig. 2b). The [macroRAFT] free of ca. $6.0 \mathrm{~g} \mathrm{~L}^{-1}$ in this system promoted chain extension of the dissolved macroRAFT agent and self-assembly of the resulting amphiphilic chains. This chain extension of water-soluble species with hydrophobic monomer, known as polymerization-induced selfassembly (PISA), has become a very popular technique in the last decade for producing polymer nano-objects with various morphologies, ${ }^{63-65}$ but is undesirable in this system because it diverts monomer away from the nanocomposite particles and reduces homogeneity in the final latexes. At $[\text { macroRAFT }]_{\text {total }}=17.2 \mathrm{~g} \mathrm{~L}^{-1}$ in $\mathrm{L}_{3}$, secondary nucleation was even more prominent than for $\mathrm{L}_{2}$ as a result of the higher $[\text { macroRAFT] }]_{\text {free }}\left(\right.$ ca. $\left.14.5 \mathrm{~g} \mathrm{~L}^{-1}\right)$. Spherical polymer particles were more numerous with lower diameters of ca. $15 \mathrm{~nm}$ (Fig. 2c), consistent with a shorter hydrophobic block length formed in the chain extension of the macroRAFT agent in solution. This lower hydrophobic volume fraction gave higher curvature at the interface of the two blocks, and therefore a lower diameter of self-assembled spheres. ${ }^{66}$ An LDH-free control experiment with similar [macroRAFT] free gave a transparent final solution, with DLS showing a single, narrowly distributed population of particles with intensity average diameter of $16 \mathrm{~nm}$ (s.d. $7 \mathrm{~nm}$, Supporting Information, Fig. S4c), which agrees well with the sizes observed in Fig. 2c. No 
particles were detected by DLS at time zero, confirming that the statistical copolymer itself does not self-assemble, and that the formation of the nano-objects occurs through the PISA process.

The systems in Fig. 2, in combination with the adsorption isotherms in Fig. 1a, were instructive for choosing appropriate [macroRAFT] free to ensure latex stability while avoiding secondary nucleation in subsequent encapsulation experiments employing $\mathrm{P}\left(\mathrm{AA}_{17.5}-c o-\mathrm{BA}_{17.5}\right)-\mathrm{R}$. The results in Fig. 2 also demonstrate the preferred sandwich morphology adopted here, with polymer growth invariably occurring on both faces of the LDH particles and negligible coverage of the LDH edges. This is presumably the equilibrium morphology, since the MA/BA 80:20 (mass/mass) polymer, with a $T_{\mathrm{g} \text {,Fox }}$ of $-9{ }^{\circ} \mathrm{C}$ (Table 2), would have been relatively mobile at the polymerization temperature.

Most nanocomposite latex particles in Fig. 2 contain multiple LDH particles, which indicates a certain extent of particle aggregation. CryoTEM images indicate that the LDH particles are reasonably well dispersed after macroRAFT adsorption and ultrasound treatment (Supporting Information, Fig. S5b), appearing essentially identical to the bare LDH particles (Supporting Information, Fig. S5a), but do show a slight inclination to aggregate rather than being completely dispersed as individual particles. CryoTEM of samples taken every hour throughout a similar polymerization $\left(\mathrm{L}_{4}\right.$, Table 2 , performed at higher [LDH] and [macroRAFT] as discussed in the next section) demonstrate that small clusters of LDH particles were already present in the $1 \mathrm{~h}$ sample and that aggregation did not noticeably increase throughout the polymerization (Supporting Information, Fig. S5c - e). Indeed, stable latexes were obtained after $4 \mathrm{~h}$ with almost negligible shift in the intensity particle size distribution throughout polymerization (DLS, Supporting Information, Fig. S5f). These data combined suggest that the multiple LDH particles observed in some latex particles were most likely present at the very start of the polymerization, due to a slight tendency of LDH to aggregate even when stabilized with macroRAFT agent. 
Daigle et al. used surfactant at a concentration below its critical micelle concentration (CMC) to minimize particle aggregation prior to the encapsulation of various nanoparticles, ${ }^{27}$ but we didn't adopt this approach due to the negative impact of surfactant on film properties. ${ }^{67,68}$

\section{Influence of monomer feed on nanocomposite morphology}

In addition to highlighting some of the important factors affecting the RAFT emulsion process, one of the central aims of this work was to attain control over the morphology of the nanocomposite particles while employing film-forming latex compositions. To further probe the influence of monomer feed on particle morphology, a series of RAFT emulsion polymerizations were conducted changing only this parameter. Targeting higher inorganic loadings by increasing $\mathrm{LDH}$ concentration to $20 \mathrm{~g} \mathrm{~L}^{-1}$, the $\mathrm{P}\left(\mathrm{AA}_{17.5}-\right.$ co- $\left.\mathrm{BA}_{17.5}\right)-\mathrm{R}$ concentration of $12 \mathrm{~g} \mathrm{~L}^{-1}$ was used in order to give a [macroRAFT] free of ca. $5 \mathrm{~g} \mathrm{~L}^{-1}$. This value was intended to give stable latexes while avoiding free particle formation based on the results in Fig. 2. With the MA/BA 80:20 (mass/mass) feed used in the last section clearly showing preference for the sandwich morphology, we sought a monomer feed which might deliver the encapsulated morphology while retaining a film-forming ability under ambient conditions. The monomer feed compositions tested are shown as $\mathrm{L}_{4}-\mathrm{L}_{7}$ in Table 2 . 

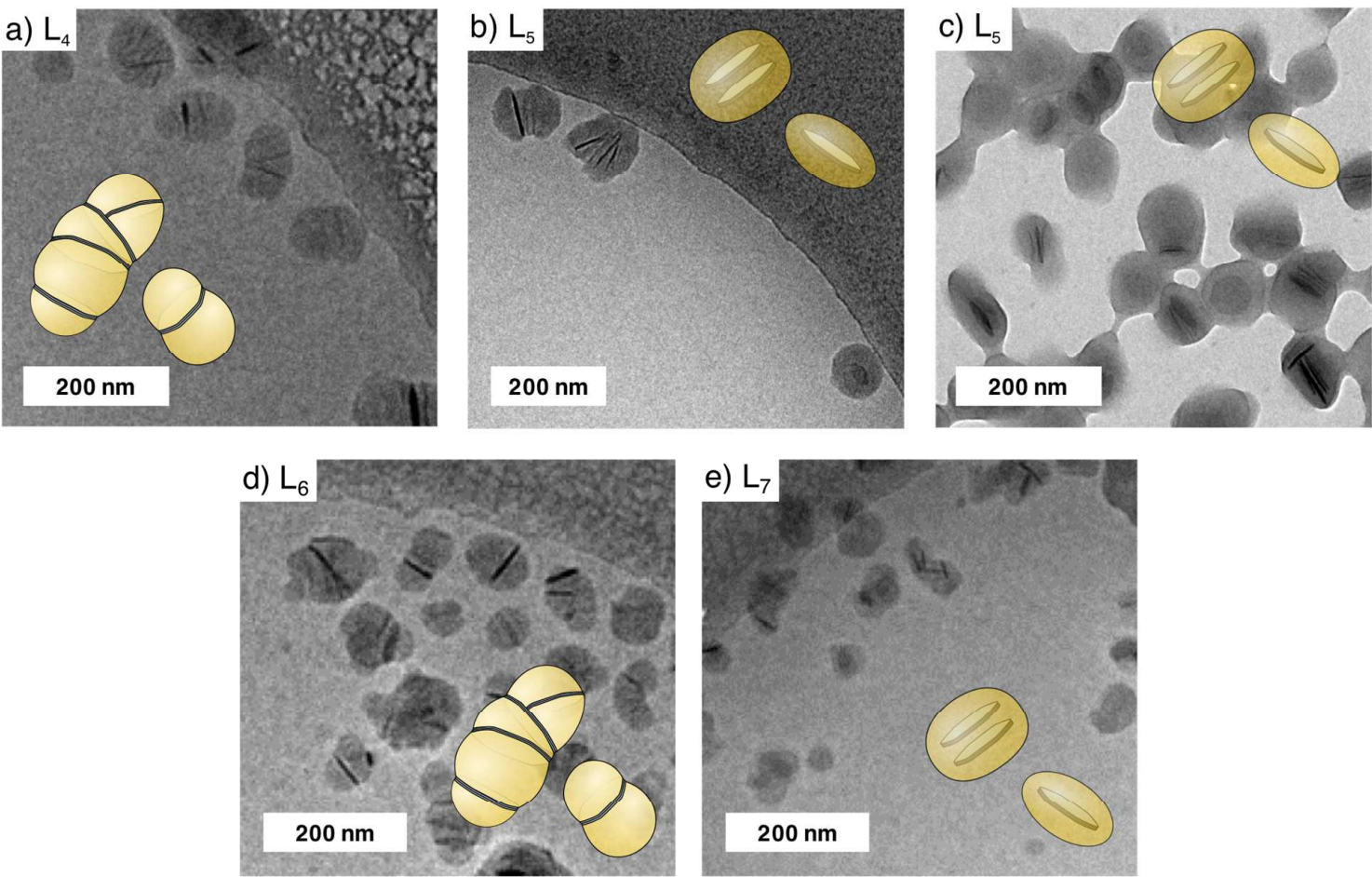

Figure 3. Monomer feed study showing final particle morphologies using $\mathrm{P}\left(\mathrm{AA}_{17.5}-c 0-\mathrm{BA}_{17.5}\right)-\mathrm{R}$ as macroRAFT agent and monomer feeds of a) $\mathrm{L}_{4}$ : MA/BA 80:20 (mass/mass); b) and c) $\mathrm{L}_{5}$ : MMA/BA 90:10 (mass/mass); d) L 6 : MMA/BA 50:50 (mass/mass); and e) $\mathrm{L}_{7}:$ MA/BA/EGDA 80:17:3 (mass/mass). All are cryoTEM images except c) which is a conventional TEM image. EGDA $=$ ethylene glycol diacrylate

The monomer feed indeed played an important role in nanocomposite morphology. The sandwich morphology observed in Fig. 2a using MA/BA 80:20 (mass/mass) was again observed here as expected, since the only change was a higher overall concentration of all components. The nonfilm-forming MMA/BA 90:10 (mass/mass) feed gave primarily the encapsulated morphology (Fig. 3b) best observed by conventional TEM (Fig. 3c) which was permitted by the $T_{\mathrm{g}}$ well above room temperature $\left(80^{\circ} \mathrm{C}\right.$, Table 2$)$. Note that we are defining encapsulation as full coverage of the 
LDH, including the edges, with a polymer shell. This experiment verified the possibility of physically entrapping the encapsulated morphology, as observed for example by Ali et al. using gibbsite particles encapsulated with a MMA/BA 10:1 (mass/mass) shell. ${ }^{36}$ The somewhat uneven polymer shell, displaying bumps and nodes best seen in Fig. 3b, has also been observed in other REEP systems employing a similar MMA/BA feed due to the high $T_{\mathrm{g}}$ limiting polymer mobility. ${ }^{34}$

A MMA/BA 50:50 (mass/mass) feed, giving $T_{\mathrm{g}, \mathrm{Fox}}=4^{\circ} \mathrm{C}$ (Table 2) reverted to the sandwich morphology presumably due to the polymerization temperature exceeding the shell $T_{\mathrm{g}}$ and therefore permitting rearrangement (Fig. 3d). Finally, the introduction of the crosslinker ethylene glycol diacrylate (EGDA) to give a feed of MA/BA/EGDA 80:17:3 was intended to keep $T_{\mathrm{g}}$ low and thereby allow film formation at room temperature, while chemically restricting the mobility of the growing shell. This indeed encouraged the encapsulated morphology (Fig. 3e), but the latex solution formed a gel-like consistency after standing at room temperature for a few days, presumably due to interparticle crosslinking via residual vinyl groups contributed by the EGDA. This monomer study therefore confirmed that polymer shells with $T_{\mathrm{g}}$ 's lower than the polymerization temperature preferred the sandwich morphology, while the encapsulated morphology could be attained if the growing shell was physically or chemically prevented from rearrangement at the expense of film-forming ability at room temperature. Secondary nucleation was also largely avoided as intended from the initial studies on the effect of macroRAFT agent concentration, and held true for all tested monomer feeds.

\section{Influence of macroRAFT agent hydrophilicity/hydrophobicity and molar mass}

The previous section demonstrated that while the encapsulated morphology was accessible by reducing the polymer mobility through using a high $T_{\mathrm{g}}$ monomer composition $\left(\mathrm{L}_{5}\right)$ or adding 
crosslinker to the monomer feed $\left(\mathrm{L}_{7}\right)$, room temperature film formation would be compromised by the high $T_{\mathrm{g}}$ and interparticle crosslinking respectively. The suite of four macroRAFT agents was therefore compared for any effect on nanocomposite morphology using the film-forming MA/BA 80:20 (mass/mass) feed (Table $1, \mathrm{~L}_{4}$ and $\mathrm{L}_{8}-\mathrm{L}_{10}$ ). The mass of macroRAFT agent was fixed at $12.0 \mathrm{~g} \mathrm{~L}^{-1}$ in each experiment, meaning that molar concentrations varied according to the molar masses of the polymers (Table 1). The concentrations of free macroRAFT agent were approximated from the adsorption isotherms (Fig. 1a) and are included in Table 2. The isotherms plotted on a molar basis are included as Figure S6 (Supporting Information).

$\mathrm{P}\left(\mathrm{AA}_{10}-\mathrm{co}-\mathrm{BA}_{5}\right)-\mathrm{R}$, although capable of stabilizing the $\mathrm{LDH}$ particles prior to polymerization, invoked rapid latex coagulation within 20 minutes of monomer addition in the emulsion polymerization $\left(\mathrm{L}_{8}\right)$. Here, [macroRAFT] free was ca. $8.7 \mathrm{~g} \mathrm{~L}^{-1}\left(5.3 \mathrm{mmol} \mathrm{L} \mathrm{L}^{-1}\right)$. Additional polymerizations were attempted using this macroRAFT agent at different [macroRAFT] $]_{\text {free }}$ (Supporting Information, Table S1, Entries $\mathrm{L}_{\mathrm{S} 1}-\mathrm{L}_{\mathrm{S} 3}$ ), and it was only at the very high [macroRAFT] $]_{\text {free }}$ of ca. $22.0 \mathrm{~g} \mathrm{~L}^{-1}\left(13.3 \mathrm{mmol} \mathrm{L}^{-1}\right)$ that stability was attained. CryoTEM of this system, however, showed very thin polymer shells around the LDH particles, and an abundance of secondary particles (Supporting Information, Fig. S7). Returning to reasonable [macroRAFT] $_{\text {free }}$ and switching to a MMA/BA 90:10 (mass/mass) feed again produced rapid coagulation (Table $\mathrm{S} 1, \mathrm{~L}_{\mathrm{S} 4}, \mathrm{~L}_{\mathrm{S} 5}$ ).

This instability was surprising given that a macroRAFT agent with the same number of AA and BA units, differing only in the nature of the RAFT agent itself, proved the most effective for encapsulating gibbsite in Ali et al.'s investigation of five different AA/BA macroRAFT agents. ${ }^{36}$ However, the symmetrical trithiocarbonate with benzyl termini used by Ali et al. is more hydrophobic than CTPPA (Scheme 1). The greater hydrophilicity of the $\mathrm{P}\left(\mathrm{AA}_{10}-\mathrm{co}-\mathrm{BA}\right)-\mathrm{R}$ used in our system may have therefore contributed to the latex instability, with literature indicating 
that excessively hydrophilic macroRAFT agents depart more easily from the inorganic surface during polymerization and compromise colloidal stability. ${ }^{26,}{ }^{33}$ The higher charge density and different surface chemistry of LDH compared with gibbsite may have also affected latex stability. In contrast, $\mathrm{P}\left(\mathrm{AA}_{23.3}-c o-\mathrm{BA}_{11.7}\right)-\mathrm{R}$, which shares the same $\mathrm{AA} / \mathrm{BA}$ ratio as $\mathrm{P}\left(\mathrm{AA}_{10^{-}}-c o-\mathrm{BA}_{5}\right)-\mathrm{R}$ but has a degree of polymerization of 35 rather than 15 , gave a stable latex $\left(\mathrm{L}_{9}\right)$ under the same conditions as $\mathrm{L}_{8}$. Here, [macroRAFT] $]_{\text {free }}$ was ca. $8.9 \mathrm{~g} \mathrm{~L}^{-1}\left(2.6 \mathrm{mmol} \mathrm{L}^{-1}\right)$, and the nanocomposite particles were again of sandwich morphology (Fig. 4a). The macroRAFT length therefore had a significant impact on the latex stability.
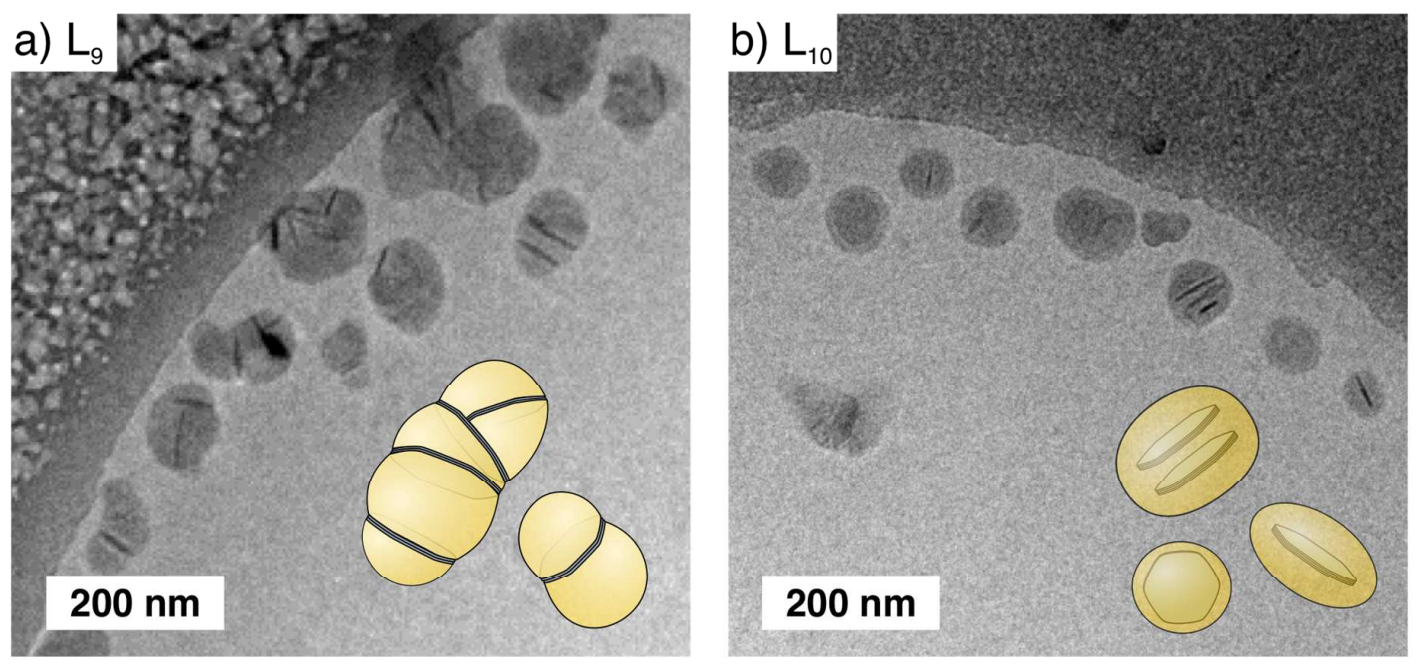

Figure 4. CryoTEM images of the final particle morphologies obtained using a) $\mathrm{P}_{\left(\mathrm{AA}_{23.3}-\mathrm{co}-\right.}$ $\left.\mathrm{BA}_{11.7}\right)-\mathrm{R}\left(\mathrm{L}_{9}\right)$, and b) $\mathrm{P}\left(\mathrm{AA}_{7.5}-c o-\mathrm{BA}_{7.5}\right)-\mathrm{R}\left(\mathrm{L}_{10}\right)$ with MA/BA 80:20 (mass/mass) monomer feed, conditions defined in Table 2.

As described in the previous section, $\mathrm{P}\left(\mathrm{AA}_{17.5}-\mathrm{co}-\mathrm{BA}_{17.5}\right)-\mathrm{R}$ gave the sandwich mosphology $\left(\mathrm{L}_{4}\right.$, Fig. 3a). In this $\mathrm{L}_{4}$ system, [macroRAFT] free was ca. $5.0 \mathrm{~g} \mathrm{~L}^{-1}\left(1.2 \mathrm{mmol} \mathrm{L}^{-1}\right)$. In contrast, $\mathrm{P}\left(\mathrm{AA}_{7.5}-c o-\mathrm{BA}_{7.5}\right)-\mathrm{R}$ produced stable latexes with a markedly different morphology $\left(\mathrm{L}_{10}\right)$. The 
edges of the LDH particles were covered with polymer and the latex particles indeed seemed to exhibit the encapsulated morphology (Fig. 4b), which is remarkable for a film-forming monomer feed composition. In $\mathrm{L}_{10}$, [macroRAFT] free was ca. $5.6 \mathrm{~g} \mathrm{~L}^{-1}\left(3.1 \mathrm{mmol} \mathrm{L}^{-1}\right)$.

Since $[\mathrm{RAFT}]$ :[initiator $]=0.5$ in all emulsion polymerization systems in the present paper, the initiator concentration in $\mathrm{L}_{10}$ was more than twice that in $\mathrm{L}_{4}$, with all other masses identical. We thought this may have affected the polymerization kinetics and thereby influenced the nanocomposite morphology, since monomer accumulation (i.e. deviation from true starved-feed conditions) has been shown to affect nanocomposite morphology in other starved-feed encapsulation systems. ${ }^{39}$ However, conversion versus time, and the proportion of monomer still unreacted at each time point, were almost identical in the two systems (Supporting Information, Fig. S8a and b). Differing degrees of monomer accumulation are therefore unlikely to account for the distinct morphologies in $\mathrm{L}_{4}$ and $\mathrm{L}_{10}$. Instead, we propose that the higher density of RAFT functions on the $\mathrm{LDH}$ in $\mathrm{L}_{10}$ may have translated to more efficient reversible chain transfer at the particle edges (as well as at the particle faces), favoring complete encapsulation rather than growth solely from the LDH faces. The defined morphologies were not supplemented with statistical analysis due to the difficulty in identifying LDH platelets oriented near-perpendicular to the electron beam, ${ }^{69}$ but further cryoTEM images showing the distinct $\mathrm{L}_{4}$ and $\mathrm{L}_{10}$ morphologies are provided in Fig. S9 (Supporting Information).

\section{Is the RAFT function important?}

The proposed roles of the macroRAFT agent in the REEP process are to provide colloidal stability, and to encourage emulsion polymerization to commence at the surface of the filler material. To the best of our knowledge, however, the role of the RAFT function itself in REEP has not been thoroughly investigated. Furthermore, the Heuts and van Herk group has reported 
effective encapsulation of MT clay particles ${ }^{37}$ and gibbsite nanoparticles ${ }^{70}$ with a high $T_{\mathrm{g}}$ shell by using conventional emulsion polymerization under starved-feed conditions. In the latter report, ${ }^{70}$ gibbsite particles were stabilized with the same short statistical copolymers used in their ATRPbased nanocomposite work, ${ }^{46,47}$ but the stabilizing polymers did not act as initiators in this system since no ATRP catalyst was used. It was sufficient to perform conventional radical polymerization under true starved-feed conditions to achieve full encapsulation. These interesting literature examples show that re-activatable functions are not always essential for successful nanocomposite particle synthesis, and motivated us to explore the contribution of the RAFT function in the present work.

The role of the RAFT function was investigated by removing it from $\mathrm{P}\left(\mathrm{AA}_{17.5}-c o-\mathrm{BA}_{17.5}\right)-\mathrm{R}$ and using the polymer in a subsequent starved-feed emulsion polymerization $\left(\mathrm{L}_{11}\right)$ under identical conditions to $\mathrm{L}_{4}$. Many methods for end group removal have been developed for RAFT polymers, ${ }^{71-74}$ but one of the most convenient remains the radical approach in which the RAFT function is replaced by an initiator-derived radical by reacting with a large excess of azo initiator. ${ }^{75}$ For acrylates, adding 2 eq. of lauryl peroxide in conjunction with the 20 eq. of azo initiator ensures full conversion while avoiding high molar mass coupling products. ${ }^{55}$ The primary lauroyl radicals are more reactive than the tertiary azo initiator radicals, and therefore generate RAFT-centred radicals which are more prone to fragment in the forward direction and release the R-group for capping with an initiator-derived radical.

This approach was performed to give the RAFT-free polymer denoted $\mathrm{P}\left(\mathrm{AA}_{17.5}-c 0-\mathrm{BA}_{17.5}\right)$ (Scheme 1). Successful end group conversion was proven by comparing the RI and UV signals by SEC, with the end group-modified polymer showing a practically complete absence of UV absorbance at $310 \mathrm{~nm}$ normally associated with the RAFT function (Fig. 5a). The IR signal in the modified polymer mirrors that of the precursor polymer, indicating that the molar mass 
distribution did not change to any measurable extent through any undesirable reactions such as radical-radical coupling between polymer chains (Fig. 5b). The modified polymer could therefore be considered as the non-reactivatable equivalent of the original macroRAFT agent, allowing the effect of the RAFT function in the encapsulating emulsion polymerization to be isolated.
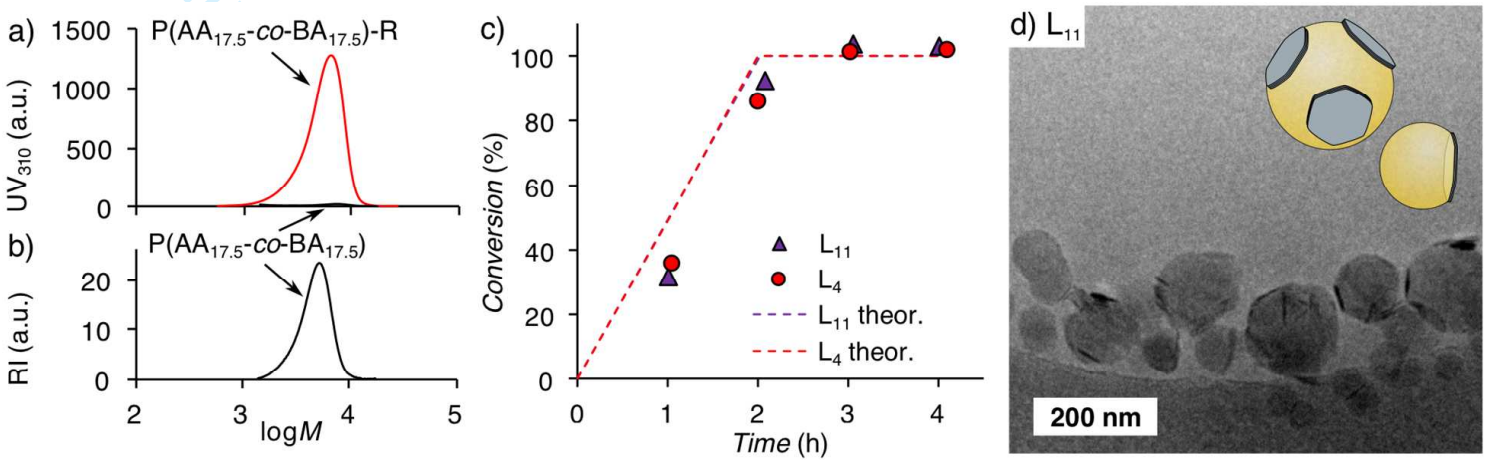

Figure 5. SEC chromatograms of $\mathrm{P}\left(\mathrm{AA}_{17.5}-c o-\mathrm{BA}_{17.5}\right)-\mathrm{R}$ and $\mathrm{P}\left(\mathrm{AA}_{17.5}-c o-\mathrm{BA}_{17.5}\right)$ prepared at ca. $2 \mathrm{~g} \mathrm{~L}^{-1}$ after methylation, with a) the UV signal at $310 \mathrm{~nm}$ showing essentially complete removal of the RAFT function, while b) the RI signal shows an essentially unchanged molar mass distribution; c) global conversion versus time for the emulsion polymerization using $\mathrm{P}\left(\mathrm{AA}_{17.5}-\mathrm{co}\right.$ $\left.\mathrm{BA}_{17.5}\right)\left(\mathrm{L}_{11}\right)$ compared with $\mathrm{P}\left(\mathrm{AA}_{17.5}-c o-\mathrm{BA}_{17.5}\right)-\mathrm{R}\left(\mathrm{L}_{4}\right)$; and d) cryoTEM image of the resulting nanocomposite particles displaying the armored morphology $\left(\mathrm{L}_{11}\right)$.

The first notable aspect of $\mathrm{L}_{11}$ was the formation of a stable latex. The RAFT function, and its proposed role in promoting polymerization from the LDH surface, was therefore not a prerequisite for stable latex formation. The conversion versus time profile also showed no discernible difference to that of the corresponding RAFT system $\mathrm{L}_{4}$ (Fig. 5c). The morphology, however, was distinctly different to that of the RAFT system. CryoTEM (Fig. 5d) revealed essentially spherical polymer particles, with LDH platelets preferentially located at the particle surface to form an armored-type morphology. Some sandwiches were evident, with the two 
polymer nodes sharing a trapped LDH platelet, but some latex particles displayed a single LDH platelet at their surface or were $\mathrm{LDH}$-free. These features contrast with $\mathrm{L}_{4}$, in which every LDH platelet, whether individually dispersed or as part of a small cluster of platelets, displayed polymer growth on both faces, and armored structures were not observed (Fig. 3a). LDH-armored latexes are interesting nanomaterials in their own right, providing access to desirable structures such as honeycomb nanocomposites. ${ }^{76}$

Comparison of $\mathrm{L}_{4}$ and $\mathrm{L}_{11}$ conclusively demonstrates that under the chosen conditions, the reactivatable RAFT function performed a critical role in attaining complete polymer coverage on the LDH faces. SEC of samples taken throughout the $\mathrm{L}_{4}$ polymerization exhibits an increase in molar mass (vs. PSt standards) with conversion, and molar masses fit reasonably well with theoretical values (Fig. 6a), confirming that chain extension indeed occurred in the RAFT systems. Dispersities rose from 1.2 to 1.7 throughout the polymerization, which was expected given that the heterogeneous nature and the high [initiator]:[RAFT] of the system would have diminished the degree of RAFT control.
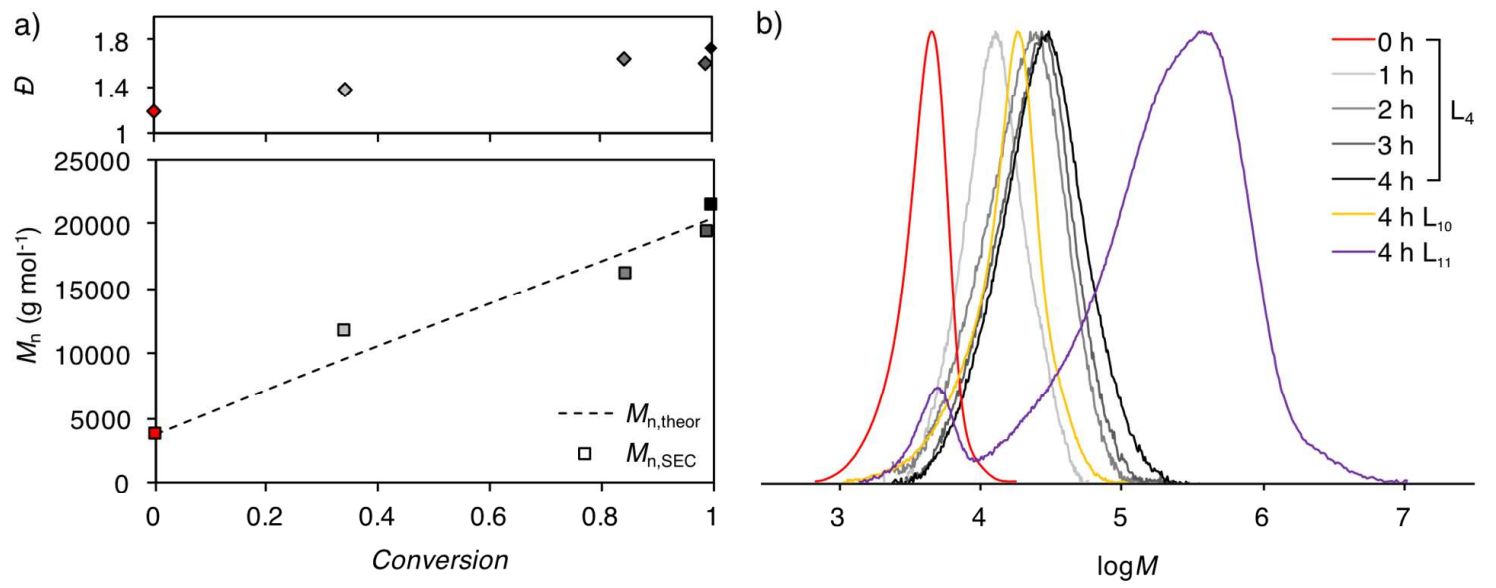

Figure 6. a) Evolution of molar mass (squares) and dispersity (diamonds) with conversion for the emulsion polymerization system using $\mathrm{P}\left(\mathrm{AA}_{17.5}-c o-\mathrm{BA}_{17.5}\right)-\mathrm{R}\left(\mathrm{L}_{4}\right)$; b) Corresponding molar mass 
distributions used to construct a), also showing the molar mass distribution for the RAFT-free system $\mathrm{L}_{11}$ at $4 \mathrm{~h}$ (purple curve) and the $\mathrm{P}\left(\mathrm{AA}_{7.5}-c o-\mathrm{BA}_{7.5}\right)-\mathrm{R}$ system $\mathrm{L}_{10}$ at $4 \mathrm{~h}$ (yellow curve). Reaction conditions defined in Table 2.

The molar mass at full conversion in $\mathrm{L}_{4}$ was approximately double that of the $\mathrm{P}\left(\mathrm{AA}_{7.5}-c o-\mathrm{BA}_{7.5}\right)$ $\mathrm{R}$ system $\left(\mathrm{L}_{10}\right.$, Fig. $6 \mathrm{~b}$ and Table 2$)$ as expected from the higher [monomer]:[RAFT] ratio. Finally, the RAFT-free system demonstrated a molar mass distribution typical of an uncontrolled radical polymerization system, with a distinct minor peak at low molar mass corresponding to the stabilizing polymer which was incapable of chain extension and therefore remained unchanged; its molar mass distribution agrees well with the $t=0$ curve of $\mathrm{L}_{4}$ in Fig. $6 \mathrm{~b}$ (i.e. that of its parent polymer carrying the RAFT function). The sole role of this polymer as stabilizer was therefore confirmed.

\section{Conclusion}

Nanocomposite latexes containing layered double hydroxide (LDH) particles were obtained by using a starved-feed emulsion process employing RAFT polymerization. Unlike most comparable nanoparticle encapsulations reported in literature, film-forming monomer feeds were chosen in this work to allow film formation under ambient conditions, which makes control over the morphology more difficult due to the high mobility of the growing polymer chains at the polymerization temperature. Controlling nanocomposite latex morphology was motivated by a desire to control nanoparticle orientation in resulting films.

Three distinct nanocomposite morphologies were successfully attained in this work by modifying the nature of the stabilizing polymer initially adsorbed on the LDH nanoparticles. CryoTEM analysis revealed that $\mathrm{LDH}$ nanoparticles stabilized with $\mathrm{P}\left(\mathrm{AA}_{17.5}-c o-\mathrm{BA}_{17.5}\right)-\mathrm{R}$ (where $\mathrm{AA}$ is 
acrylic acid, BA is $n$-butyl acrylate, and R is the RAFT function) gave the sandwich morphology when a methyl acrylate (MA)/BA 80:20 (mass/mass) feed was used. Here, polymer domains only on the nanoparticle faces is assumed to be energetically preferable to encapsulation, since the low $T_{\mathrm{g}}$ polymer should be mobile enough to minimize its surface energy at the polymerization temperature. Changing to a high $T_{\mathrm{g}}$ monomer feed, or a feed incorporating a small amount of crosslinker, provided access to the encapsulated morphology but these latexes were no longer film-forming.

Remarkably, the encapsulated morphology could also be achieved with the film-forming MA/BA 80:20 (mass/mass) monomer composition by using the shorter stabilizing polymer $\mathrm{P}\left(\mathrm{AA}_{7.5}-\mathrm{co}-\right.$ $\mathrm{BA}_{7.5}$ )-R. Attainment of a fully-encapsulating polymer layer was somehow encouraged in this system, which we tentatively ascribe to the higher density of RAFT functions promoting more efficient polymer growth particularly around the particle edges.

A third type of nanocomposite particles, with armored morphology, were produced by removing the RAFT function from the stabilizing polymer $\mathrm{P}\left(\mathrm{AA}_{17.5}-c o-\mathrm{BA}_{17.5}\right)-\mathrm{R}$ prior to its adsorption on LDH. Inorganic-armored latexes are desirable nanocomposites in their own right, and their attainment in this case unequivocally highlights the importance of the RAFT functions in providing re-activatable sites from which chain extension can proceed to give even polymer growth from both LDH faces in the RAFT-bearing systems.

In addition to accessing three different film-forming nanocomposite morphologies, the effect of molar mass and hydrophilic/hydrophobic balance were isolated in the adsorption of four macroRAFT agents on LDH. Increasing the BA content of the macroRAFT agent at fixed molar mass significantly increased the amount required for LDH charge neutralization (by 50\%), and increasing molar mass at a fixed AA/BA ratio had a similar albeit weaker effect ( $27 \%$ increase). The adsorption behavior was combined with observations of latex stability, secondary nucleation, 
and monomer conversion to generate stable emulsion polymerization systems devoid of free polymer particles which reached full conversion at relatively short reaction times. We expect these findings to be broadly applicable to the encapsulation of other nanoparticles.

The microstructure and mechanical properties of nanocomposite films made from the three different latex morphologies have been studied in detail and are the subject of a separate publication.

\section{Supporting Information}

Synthesis, and ${ }^{1} \mathrm{H}$ and ${ }^{13} \mathrm{C}$ NMR spectra, of 4-cyano-4-thiothiopropylsulfanyl pentanoic acid (CTPPA), SEC traces and conversion versus time for macroRAFT agent synthesis, DLS and XRD of bare LDH particles, cryoTEM and DLS of samples taken throughout the $\mathrm{L}_{4}$ polymerization, adsorption isotherms on a molar basis, table of additional emulsion polymerizations, cryoTEM of $\mathrm{L}_{\mathrm{S} 3}$, and monomer consumption profiles for $\mathrm{L}_{4}$ and $\mathrm{L}_{10}$.

\section{Acknowledgements}

Financial support from ANR-11-JS08-0013 (PolyHydRAFT) is gratefully acknowledged. The authors would like to thank Ana Maria Cenacchi Perreira and Bastian Ebeling for helpful discussions, and Pierre-Yves Dugas and the Centre Technologique des Microstructures $(\mathrm{CT} \mu)$, Claude Bernard Lyon 1 University, for cryoTEM training and support.

\section{References}

1. Hanemann, T.; Szabó, D. V. Polymer-Nanoparticle Composites: From Synthesis to Modern Applications. Materials 2010, 3, 3468-3517.

2. Paula, D. R.; Robesonb, L. M. Polymer nanotechnology: Nanocomposites. Polymer 2008, 49, 3187-3204.

3. Costantino, U.; Leroux, F.; Nocchetti, M.; Mousty, C., LDH in physical, chemical, biochemical and life science. In Handbook of Clay Science, 2nd Part B : Techniques and 
Applications ed.; Fa1za Bergaya, G. L., Ed. Elsevier: Amsterdam, 2013; Vol. 5, Part B, pp 765791.

4. Forano, C.; Costantino, U.; Prevot, V.; Taviot Gueho, C., Layered Double Hydroxides. In Handbook of Clay Science, Fa1za Bergaya, G. L., Ed. Elsevier: Amsterdam, 2013; Vol. 5, Part A, pp 745-783.

5. Taviot-Guého, C.; Prévot, V.; Forano, C.; Renaudin, G.; Mousty, C.; Leroux, F. Tailoring Hybrid Layered Double Hydroxides for the Development of Innovative Applications. Adv. Funct. Mater. 2017, 10.1002/adfm.201703868.

6. Gao, Y.; Wu, J.; Wang, Q.; Wilkie, C. A.; O'Hare, D. Flame retardant polymer/layered double hydroxide nanocomposites J. Mater. Chem. A 2014, 2, 10996-11016.

7. Matusinovic, Z.; Wilkie, C. A. Fire retardancy and morphology of layered double hydroxide nanocomposites: a review $J$. Mater. Chem. 2012, 22, 18701-18704.

8. Tsai, T.-Y.; Naveen, B.; Shiu, W.-C.; Lu, S.-W. An advanced preparation and characterization of the PET/MgAl-LDH nanocomposites RSC Adv. 2014, 4, 25683-25691.

9. Stimpfling, T.; Leroux, F.; Hintze-Bruening, H. Phosphate-Based Organic Molecules Interleaved with Layered Double Hydroxide : Unraveling the Roles of Host Cations and the Guest-Inhibiting Effect in Aluminum Corrosion Protection. Eur. J. Inorg. Chem. 2012, 53965404.

10. Zheludkevich, M. L.; Poznyak, S. K.; Rodrigues, L. M.; Raps, D.; Hack, T.; Dick, L. F.; Nunes, T.; Ferreira, M. G. S. Active protection coatings with layered double hydroxide nanocontainers of corrosion inhibitor. Corros. Sci. 2010, 52, 602-611.

11. Costa, F. R.; Saphiannikova, M.; Wagenknecht, U.; Heinrich, G. Layered Double Hydroxide Based Polymer Nanocomposites. Adv. Polym. Sci. 2008, 210, 101-168.

12. Illaik, A.; Taviot-Gueho, C.; Lavis, J.; Cornmereuc, S.; Verney, V.; Leroux, F. Unusual Polystyrene Nanocomposite Structure Using Emulsifier-Modified Layered Double Hydroxide as Nanofiller. Chem. Mater. 2008, 20 (15), 4854-4860.

13. Leroux, F.; Besse, J.-P. Polymer Interleaved Layered Double Hydroxide: A New Emerging Class of Nanocomposites. Chem. Mater. 2001, 13 (10), 3507-3515.

14. Roland-Swanson, C.; Besse, J. P.; Leroux, F. Polymerization of Sulfopropyl Methacrylate, a Surface Active Monomer, within Layered Double Hydroxide. Chem. Mater. 2004, 16 (25), 5512-5517.

15. Bao, Y.-Z.; Huang, Z.-M.; Weng, Z.-X. Preparation and Characterization of Poly(vinyl chloride)/Layered Double Hydroxides Nanocomposite via In Situ Suspension Polymerization. $J$. Appl. Polym. Sci. 2006, 102 (2), 1471-1477.

16. Ding, P.; Qu, B. Synthesis and characterization of exfoliated polystyrene/ZnAl layered double hydroxide nanocomposite via emulsion polymerization. J. Colloid Interface Sci. 2005, 291 (1), 13-18.

17. Ding, P.; Qu, B. Synthesis and characterization of polystyrene/layered double-hydroxide nanocomposites via in situ emulsion and suspension polymerization. J. Appl. Polym. Sci. 2006, 101 (6), 3758-3766.

18. Chen, W.; Feng, L.; Qu, B. In situ synthesis of poly(methyl methacrylate)/MgAl layered double hydroxide nanocomposite with high transparency and enhanced thermal properties. Solid State Commun. 2004, 130 (3-4), 259-263.

19. Qiu, L.; Chen, W.; Qu, B. Exfoliation of layered double hydroxide in polystyrene by insitu atom transfer radical polymerization using initiator-modified precursor. Colloid Polym. Sci. 2005, 283 (11), 1241-1245. 
20. Qiu, L.; Qu, B. Preparation and characterization of surfactant-free polystyrene/layered double hydroxide exfoliated nanocomposite via soap-free emulsion polymerization. J. Colloid Interface Sci. 2006, 301 (2), 347-351.

21. Vaysse, C.; Guerlou-Demourgues, L.; Delmas, C.; Duguet, E. Tentative Mechanisms for Acrylate Intercalation and in Situ Polymerization in Nickel-Based Layered Double Hydroxides. Macromolecules 2004, 37 (1), 45-51.

22. Ding, P.; Zhang, M.; Gai, J.; Qu, B. Homogeneous dispersion and enhanced thermal properties of polystyrene-layered double hydroxide nanocomposites prepared by in situ reversible addition-fragmentation chain transfer (RAFT) polymerization. J. Mater. Chem. 2007, 17 (11), $1117-1122$.

23. Zetterlund, P. B.; Thickett, S. C.; Perrier, S.; Bourgeat-Lami, E.; Lansalot, M. Controlled/Living Radical Polymerization in Dispersed Systems: An Update. Chem. Rev. 2015, 115 (18), 9745-800.

24. Bourgeat-Lami, E.; D'Agosto, F.; Lansalot, M., Synthesis of Nanocapsules and Polymer/Inorganic Nanoparticles Through Controlled Radical Polymerization At and Near Interfaces in Heterogeneous Media. In Controlled Radical Polymerization at and from Solid Surfaces, Vana, P., Ed. Springer International Publishing: Cham, 2016; pp 123-161.

25. Perreira, A. C.; Pearson, S.; Kostadinova, D.; Leroux, F.; D'Agosto, F.; Lansalot, M.; Bourgeat-Lami, E.; Prevot, V. Nanocomposite latexes containing layered double hydroxides via RAFT-assisted encapsulating emulsion polymerization. Polym. Chem. 2017, 8 (7), 1233-1243.

26. Nguyen, D.; Zondanos, H. S.; Farrugia, J. M.; Serelis, A. K.; Such, C. H.; Hawkett, B. S. Pigment encapsulation by emulsion polymerization using macro-RAFT copolymers. Langmuir 2008, 24 (5), 2140-2150.

27. Daigle, J.-C.; Claverie, J. P. A Simple Method for Forming Hybrid Core-Shell Nanoparticles Suspended in Water. J. Nanomater. 2008, 2008, 8.

28. Bourgeat-Lami, E.; França, A. J. P. G.; Chaparro, T. C.; Silva, R. D.; Dugas, P. Y.; Alves, G. M.; Santos, A. M. Synthesis of Polymer/Silica Hybrid Latexes by Surfactant-Free RAFTMediated Emulsion Polymerization. Macromolecules 2016, 49 (12), 4431-4440.

29. Li, K.; Dugas, P.-Y.; Bourgeat-Lami, E.; Lansalot, M. Polymer-encapsulated $\gamma$-Fe2O3 nanoparticles prepared via RAFT-mediated emulsion polymerization. Polymer 2016, 106 (Supplement C), 249-260.

30. Nguyen, D.; Pham, B. T. T.; Huynh, V.; Kim, B. J.; Pham, N. T. H.; Bickley, S. A.; Jones, S. K.; Serelis, A.; Davey, T.; Such, C.; Hawkett, B. S. Monodispersed polymer encapsulated superparamagnetic iron oxide nanoparticles for cell labeling. Polymer 2016, 106 (Supplement C), 238-248.

31. Zgheib, N.; Putaux, J. L.; Thill, A.; Bourgeat-Lami, E.; D'Agosto, F.; Lansalot, M. Cerium oxide encapsulation by emulsion polymerization using hydrophilic macroRAFT agents. Polym. Chem. 2013, 4 (3), 607-614.

32. Das, P.; Claverie, J. P. Synthesis of single-core and multiple-core core-shell nanoparticles by RAFT emulsion polymerization: Lead sulfide-copolymer nanocomposites. J. Polym. Sci. Part A: Polym. Chem. 2012, 50 (14), 2802-2808.

33. Das, P.; Zhong, W.; Claverie, J. P. Copolymer nanosphere encapsulated cds quantum dots prepared by RAFT copolymerization: Synthesis, characterization and mechanism of formation. Colloid Polym. Sci. 2011, 289 (14), 1519-1533.

34. Ali, S. I.; Heuts, J. P. A.; van Herk, A. M. Controlled Synthesis of Polymeric Nanocapsules by RAFT-Based Vesicle Templating. Langmuir 2010, 26 (11), 7848-7858. 
35. Ali, S. I.; Heuts, J. P. A.; van Herk, A. M. Vesicle-templated pH-responsive polymeric nanocapsules. Soft Matter 2011, 7 (11), 5382-5390.

36. Ali, S. I.; Heuts, J. P. A.; Hawkett, B. S.; van Herk, A. M. Polymer Encapsulated Gibbsite Nanoparticles: Efficient Preparation of Anisotropic Composite Latex Particles by RAFT-Based Starved Feed Emulsion Polymerization. Langmuir 2009, 25 (18), 10523-10533.

37. Mballa Mballa, M. A.; Ali, S. I.; Heuts, J. P.; Van Herk, A. M. Control of the anisotropic morphology of latex nanocomposites containing single montmorillonite clay particles prepared by conventional and reversible additionfragmentation chain transfer based emulsion polymerization. Polym. Int. 2012, 61 (6), 861-865.

38. Nguyen, D.; Such, C. H.; Hawkett, B. S. Polymer coating of carboxylic acid functionalized multiwalled carbon nanotubes via reversible addition-fragmentation chain transfer mediated emulsion polymerization. J. Polym. Sci. Part A: Polym. Chem. 2013, 51 (2), 250-257.

39. Zhong, W.; Zeuna, J. N.; Claverie, J. P. A versatile encapsulation method of noncovalently modified carbon nanotubes by RAFT polymerization. J. Polym. Sci. Part A: Polym. Chem. 2012, 50 (21), 4403-4407.

40. Huynh, V. T.; Nguyen, D.; Such, C. H.; Hawkett, B. S. Polymer coating of graphene oxide via reversible addition-fragmentation chain transfer mediated emulsion polymerization. $J$. Polym. Sci. Part A: Polym. Chem. 2015, 53 (12), 1413-1421.

41. Asua, J. M. Mapping the Morphology of Polymer-Inorganic Nanocomposites Synthesized by Miniemulsion Polymerization. Macromol. Chem. Phys. 2014, 215 (5), 458-464.

42. Colver, P. J.; Colard, C. A. L.; Bon, S. A. F. Multilayered Nanocomposite Polymer Colloids Using Emulsion Polymerization Stabilized by Solid Particles. J. Am. Chem. Soc. 2008, 130 (50), 16850-16851.

43. Percy, M. J.; Amalvy, J. I.; Barthet, C.; Armes, S. P.; Greaves, S. J.; Watts, J. F.; Wiese, H. Surface characterization of vinyl polymer-silica colloidal nanocomposites using X-ray photoelectron spectroscopy. J. Mater. Chem. 2002, 12 (3), 697-702.

44. Mičušík, M.; Bonnefond, A.; Reyes, Y.; Bogner, A.; Chazeau, L.; Plummer, C.; Paulis, M.; Leiza, J. R. Morphology of Polymer/Clay Latex Particles Synthesized by Miniemulsion Polymerization: Modeling and Experimental Results. Macromol. React. Eng. 2010, 4 (6-7), $432-$ 444.

45. Herk, A. M. v. Polymer Encapsulation of Single Clay Platelets by Emulsion Polymerization Approaches, Thermodynamic, and Kinetic Factors. Macromol. React. Eng. 2016, 10 (1), 22-28.

46. Loiko, O.; Spoelstra, A. B.; Van Herk, A.; Meuldijk, J.; Heuts, J. P. A. ATRP mediated encapsulation of Gibbsite: fixation of the morphology using a cross-linker. Polym. Chem. 2017.

47. Loiko, O. P.; Spoelstra, A. B.; van Herk, A. M.; Meuldijk, J.; Heuts, J. P. A. An ATRPbased approach towards water-borne anisotropic polymer-Gibbsite nanocomposites. Polym. Chem. 2016, 7 (20), 3383-3391.

48. Pavlovic, M.; Adok-Sipiczki, M.; Nardin, C.; Pearson, S.; Bourgeat-Lami, E.; Prevot, V.; Szilagyi, I. Effect of MacroRAFT Copolymer Adsorption on the Colloidal Stability of Layered Double Hydroxide Nanoparticles. Langmuir 2015, 31 (46), 12609-12617.

49. Xu, Z. P.; Stevenson, G. S.; Lu, C.-Q.; Lu, G. Q.; Bartlett, P. F.; Gray, P. P. Stable Suspension of Layered Double Hydroxide Nanoparticles in Aqueous Solution. J. Am. Chem. Soc. 2006, 128 (1), 36-37.

50. Xu, Z. P.; Stevenson, G.; Lu, C.-Q.; Lu, G. Q. Dispersion and Size Control of Layered Double Hydroxide Nanoparticles in Aqueous Solutions. J. Phys. Chem. B 2006, 110 (34), $16923-$ 16929. 
51. Xu, X.; Smith, A. E.; Kirkland, S. E.; McCormick, C. L. Aqueous RAFT Synthesis of pHResponsive Triblock Copolymer mPEO-PAPMA-PDPAEMA and Formation of Shell CrossLinked Micelles. Macromolecules 2008, 41 (22), 8429-8435.

52. Bouhadir, G.; Legrand, N.; Quiclet-Sire, B.; Zard, S. Z. A new practical synthesis of tertiary S-alkyl dithiocarbonates and related derivatives. Tetrahedron Lett. 1999, 40 (2), 277-280. 53. Thang, S. H.; Chong, Y. K.; Mayadunne, R. T. A.; Moad, G.; Rizzardo, E. A novel synthesis of functional dithioesters, dithiocarbamates, xanthates and trithiocarbonates. Tetrahedron Lett. 1999, 40 (12), 2435-2438.

54. Couvreur, L.; Lefay, C.; Belleney, J.; Charleux, B.; Guerret, O.; Magnet, S. First Nitroxide-Mediated Controlled Free-Radical Polymerization of Acrylic Acid. Macromolecules 2003, 36 (22), 8260-8267.

55. Chen, M.; Moad, G.; Rizzardo, E. Thiocarbonylthio end group removal from RAFTsynthesized polymers by a radical-induced process. J. Polym. Sci., Part A: Polym. Chem. 2009, 47 (23), 6704-6714.

56. McLeary, J. B.; Calitz, F. M.; McKenzie, J. M.; Tonge, M. P.; Sanderson, R. D.; Klumperman, B. Beyond Inhibition: A 1H NMR Investigation of the Early Kinetics of RAFTMediated Polymerization with the Same Initiating and Leaving Groups. Macromolecules 2004, 37 (7), 2383-2394.

57. McLeary, J. B.; Tonge, M. P.; Klumperman, B. A Mechanistic Interpretation of Initialization Processes in RAFT-Mediated Polymerization. Macromol. Rapid Commun. 2006, 27 (15), 1233-1240.

58. Muller, D.; Malmsten, M.; Tanodekaew, S.; Booth, C. Adsorption of Diblock Copolymers of Poly(ethylene oxide) and Poly(lactide) at Hydrophilic Silica from Aqueous Solution. $J$. Colloid Interface Sci. 2000, 228 (2), 317-325.

59. Szilagyi, I.; Trefalt, G.; Tiraferri, A.; Maroni, P.; Borkovec, M. Polyelectrolyte adsorption, interparticle forces, and colloidal aggregation. Soft Matter 2014, 10 (15), 2479-2502.

60. Holthoff, H.; Egelhaaf, S. U.; Borkovec, M.; Schurtenberger, P.; Sticher, H. Coagulation Rate Measurements of Colloidal Particles by Simultaneous Static and Dynamic Light Scattering. Langmuir 1996, 12 (23), 5541-5549.

61. Brandrup, J.; Immergut, E. H.; Grulke, E. A., Polymer Handbook. Wiley: 1999.

62. Fox, T. G. Influence of diluent and of copolymer composition on the glass transition temperature of a polymer system. Bulletin of the American Physics Society 1956, 1, 123.

63. Canning, S. L.; Smith, G. N.; Armes, S. P. A Critical Appraisal of RAFT-Mediated Polymerization-Induced Self-Assembly. Macromolecules 2016, 49 (6), 1985-2001.

64. Jennings, J.; He, G.; Howdle, S. M.; Zetterlund, P. B. Block copolymer synthesis by controlled/living radical polymerisation in heterogeneous systems. Chem. Soc. Rev. 2016, 45 (18), 5055-5084.

65. Lansalot, M.; Rieger, J.; D'Agosto, F., Polymerization-Induced Self-Assembly: The Contribution of Controlled Radical Polymerization to The Formation of Self-Stabilized Polymer Particles of Various Morphologies. In Macromolecular Self-assembly, Billon, L., Borisov, O., Eds. John Wiley \& Sons, Inc.: 2016; pp 33-82.

66. Mai, Y.; Eisenberg, A. Self-assembly of block copolymers. Chem. Soc. Rev. 2012, 41 (18), 5969-5985.

67. Butler, L. N.; Fellows, C. M.; Gilbert, R. G. Effect of surfactant systems on the water sensitivity of latex films. J. Appl. Polym. Sci. 2004, 92 (3), 1813-1823. 
68. Jiang, B.; Tsavalas, J. G.; Sundberg, D. C. Water whitening of polymer films: Mechanistic studies and comparisons between water and solvent borne films. Prog. Org. Coat. 2017, 105 (Supplement C), 56-66.

69. Voorn, D. J.; Ming, W.; van Herk, A. M. Clay Platelets Encapsulated Inside Latex Particles. Macromolecules 2006, 39 (14), 4654-4656.

70. Loiko, O. P.; Spoelstra, A. B.; van Herk, A. M.; Meuldijk, J.; Heuts, J. P. A. Encapsulation of unmodified Gibbsite via conventional emulsion polymerisation using charged co-oligomers. RSC Adv. 2016, 6 (84), 80748-80755.

71. Jesson, C. P.; Pearce, C. M.; Simon, H.; Werner, A.; Cunningham, V. J.; Lovett, J. R.; Smallridge, M. J.; Warren, N. J.; Armes, S. P. H2O2 Enables Convenient Removal of RAFT End-Groups from Block Copolymer Nano-Objects Prepared via Polymerization-Induced SelfAssembly in Water. Macromolecules 2017, 50 (1), 182-191.

72. Moad, G.; Rizzardo, E.; Thang, S. H. End-functional polymers, thiocarbonylthio group removal/transformation and reversible addition-fragmentation-chain transfer (RAFT) polymerization. Polym. Int. 2011, 60 (1), 9-25.

73. Willcock, H.; O'Reilly, R. K. End group removal and modification of RAFT polymers. Polym. Chem. 2010, 1 (2), 149-157.

74. Carmean, R. N.; Figg, C. A.; Scheutz, G. M.; Kubo, T.; Sumerlin, B. S. Catalyst-Free Photoinduced End-Group Removal of Thiocarbonylthio Functionality. ACS Macro Lett. 2017, 6 (2), 185-189.

75. Perrier, S.; Takolpuckdee, P.; Mars, C. A. Reversible Addition-Fragmentation Chain Transfer Polymerization: End Group Modification for Functionalized Polymers and Chain Transfer Agent Recovery. Macromolecules 2005, 38 (6), 2033-2036.

76. Veschambres, C.; Halma, M.; Bourgeat-Lami, E.; Chazeau, L.; Dalmas, F.; Prevot, V. Layered double hydroxides: Efficient fillers for waterborne nanocomposite films. Appl. Clay Sci. 2016, 130 (Supplement C), 55-61. 